\title{
LA VINCULACIÓN POSITIVA DE LOS PODERES PÚBLICOS A LOS DERECHOS FUNDAMENTALES
}

\author{
JUAN CARLOS GAVARA DE CARA \\ Profesor Titular de Derecho Constitucional \\ Universidad Autónoma de Barcelona
}

SUMARIO

I. La vinculación positiva de carácter subjetivo del poder legislativo a los derechos fundamentales.

II. La vinculación positiva de carácter subjetivo del poder ejecutivo.

III. La vinculación positiva del poder judicial a los derechos fundamentales.

IV. La incidencia y las consecuencias estructurales y funcionales de la vinculación positiva de carácter objetivo en los derechos fundamentales.

V. Los efectos de la vinculación positiva de carácter objetivo en los derechos de defensa.

VI. Los efectos de la vinculación positiva de carácter objetivo en los derechos de prestación.

En la Constitución Española, la vinculación a los derechos fundamentales opera a partir de un doble esquema. En primer lugar, el art. 9.1 CE establece y permite deducir la vinculación negativa a los derechos fundamentales, es decir, el deber de abstenerse de cualquier actuación que vulnere la Constitución, incluidos eventualmente los derechos fundamentales, y que afecta tanto a los poderes públicos como a los ciudadanos. En segundo lugar, el art. 53.1 CE establece de modo expreso y permite deducir una vinculación positiva a los derechos fundamentales que afecta exclusivamente a los poderes públicos y que se traduce en un deber general de realizar las funciones de 
acuerdo con la Constitución y un mandato de desplegar la eficacia de los derechos fundamentales en el sentido de establecer su realización plena ${ }^{1}$.

En consecuencia, se debe destacar que las persones privadas están vinculadas y deben ejercer como destinatarios de los derechos fundamentales de un modo directo en el primero de los sentidos, es decir, solo se les puede exigir una vinculación negativa, de forma que se deben abstener de realizar actos que perjudiquen el contenido y ámbito de protección de los derechos fundamentales, cuyo contenido constitucional permite derivar un inexcusable cumplimiento, pero no se les pueda exigir que realicen acciones positivas específicas de cumplimiento, protección y dotación de eficacia a los derechos fundamentales, es decir, no se les puede exigir una vinculación positiva a los derechos fundamentales al menos como una obligación derivada directamente de la Constitución ${ }^{2}$. Por el contrario, los poderes públicos están vinculados negativa y positivamente en los términos previstos por la Constitución y el ordenamiento jurídico.

La vinculación positiva se puede estructurar a partir de un doble análisis, es decir, de sus consecuencias de carácter subjetivo con la finalidad de determinar los sujetos afectados, es decir, los poderes públicos, y las consecuencias para sus funciones en el ámbito de los derechos fundamentales y, en segundo lugar, la vinculación positiva de carácter objetivo, con la finalidad de determinar los efectos que produce materialmente en los derechos fundamentales a partir de la distinción entre derechos de defensa y derechos de prestación y las repercusiones para los sujetos privados afectados por las acciones positivas de protección y dotación de eficacia desarrolladas y adoptadas por el poder público.

Con todo, se debe destacar, por una parte, que el tema principal de la vinculación positiva a los derechos fundamentales es la necesidad de su mediación y articulación a través de la ley, pero al mismo tiempo, por otra parte, que el elemento que permite posibilitar el control de la actividad de los poderes públicos en dicho ámbito reside en la obligación de justificar la adopción abstracta y, sobre todo, concreta de los instrumentos de vinculación positiva, hasta el punto que el tema de la motivación del acto adoptado se

1 Sobre la distinción entre vinculación negativa y positiva a los derechos fundamentales, con claridad STC 101/1983 FJ 4. En ocasiones el Tribunal Constitucional ha derivado del art. 9.1 CE un deber positivo de efectividad de los derechos fundamentales en su vigencia en la vida social (STC 18/1984 FJ 6). Sobre esta distinción, vid. BILBAO UBILLOS, J. M., La eficacia de los derechos fundamentales en las relaciones entre particulares. Análisis de la jurisprudencia del Tribunal Constitucional, CEC, Madrid, 1997, pp. 351 y ss. Sobre la vinculación positiva y su alcance, ALÁEZ CORRAL, B., en AAVV, Teoría general de los derechos fundamentales en la Constitución Española de 1978, Tecnos, Madrid, 2004, p. 182.

2 En este sentido, en relación con el derecho a la educación, a un empresario se le puede exigir que no impida o prohíba que sus trabajadores sigan sus estudios, pero no se le puede imponer la obligación de satisfacer de forma incondicionada dicho derecho a efectos de una solicitud de cambio de turno para la asistencia a clase de un trabajador dentro del cumplimiento de las obligaciones contractuales en una relación laboral (STC 129/1989 FJ 5). 
convierte en la principal vía de control de la incidencia de las actuaciones de los poderes ejecutivos y judicial en materia de derechos fundamentales ${ }^{3}$.

\section{LA VINCULACIÓN POSITIVA DE CARÁCTER SUBJETIVO DEL PODER LEGISLATIVO A LOS DERECHOS FUNDAMENTALES}

La vinculación del poder legislativo a los derechos fundamentales es la más importante de las de carácter subjetivo, no solo por el hecho de que la ley constituye la forma principal de desarrollo y concreción de los derechos fundamentales $^{4}$, sino debido a las repercusiones que puede ocasionar en la actividad de los otros poderes públicos y en el alcance de su vinculación jurídica en materia de derechos fundamentales. En este sentido, la ley establece el marco de actuación de los otros poderes del Estado y fija el alcance de la vinculación positiva, constituyendo la pieza central y más importante para determinar la obligación de protección a los derechos fundamentales, ya que estructura las funciones de los órganos aplicadores del Derecho en el caso concreto.

En relación con los derechos fundamentales, el legislador tiene atribuidas diversas funciones que pueden ir desde un mandato directo o implícito de inactividad en relación con determinados derechos, pasando por la autorización para la limitación del ejercicio de los derechos fundamentales, hasta, finalmente, la posibilidad de configuración para posibilitar el ejercicio del derecho fundamental y la consiguiente obligación expresa de adoptar dichas medidas legislativas, así como la eventual actividad legislativa en materia de derechos fundamentales que puede recaer en el ámbito de la oportunidad política para decidir si se realiza o no el desarrollo normativo y hasta que punto o intensidad5.

La ley es el instrumento principal de articulación de la vinculación positiva a los derechos fundamentales. Sin embargo, los procedimientos ordinarios de control de constitucionalidad de la ley no son específicos para la protección de los derechos fundamentales y tampoco se encuentre prevista en nuestro sistema constitucional expresamente la posibilidad de presentación del recurso de amparo frente a leyes como procedimiento especializado para

3 Sobre la fundamentación constitucional de la obligación de motivación de las decisiones de los poderes públicos, KISCHEL, U., Die Begründung. Zur Erläuterung staatlicher Entscheidungen gegenüber dem Bürger, Mohr Siebeck, Tübingen, 2003, pp. 63 y ss.

4 Sobre la apertura de los derechos fundamentales a las decisiones del legislador ordinario, JESTAEDT, M., Grundrechtsentfaltung im Gesetz. Studien zur Interdependenz von Grundrechtsdogmatik und Rechtsgewinnungstheorie, Tübingen, Mohr Siebeck, 1999, pp. 29 y ss.

5 Sobre el deber de legislar en materia de derechos fundamentales no es abundante el tratamiento en nuestra doctrina, aunque se puede destacar la obra de GÓMEZ PUENTE, M., La inactividad del legislador. Una realidad susceptible de control, McGraw-Hill, Madrid, 1997, pp. 44 y ss. En general, sobre el papel del legislador en la vinculación positiva, ALÁEZ CORRAL, B, en AAVV, Teoría general de los derechos fundamentales en la Constitución Española de 1978, op. cit., pp. 183 y ss. 
la protección de derechos fundamentales. En cualquier caso, se debe tener en cuenta el hecho de que la Constitución permite la ampliación de competencia del Tribunal Constitucional (art. 161.1.d CE) mediante decisión legislativa, de forma que es susceptible de incorporarse a la LOTC procedimientos para el control de constitucionalidad de las omisiones legislativas o procedimientos de amparo directo frente a leyes. Desde otra perspectiva, el amparo frente a una omisión legislativa siempre es reconducible a una necesidad de resolución de un caso en base a la aplicación directa del derecho fundamental, es decir, a partir de la aplicación del precepto constitucional en caso de laguna legislativa en un supuesto que afecte a un derecho fundamental específico (art. 53.1 CE).

El Tribunal Constitucional reconoció desde sus primeras sentencias que si bien solo se admiten en amparo pretensiones directas dirigidas a reestablecer o preservar los derechos fundamentales, también es cierto que el art. 55.2 LOTC permite estimar un recurso de amparo por la causa de que la ley aplicada infrinja de forma inconstitucional un derecho fundamental ${ }^{6}$, pero tan solo adopta dichos pronunciamientos cuando sea imprescindible para corregir la lesión de un derecho fundamental que sea imputable directamente a la aplicación del precepto legal contrario a la Constitución. Para pronunciarse sobre esta constitucionalidad, el Tribunal Constitucional debe constatar con anterioridad que mediante la aplicación del precepto se ha producido la lesión del derecho fundamental? .

Precisamente en este punto reside la dificultad inicial del control en amparo de cualquier decisión legislativa de concreción de la vinculación positiva a un derecho fundamental específico, ya que implica la articulación de alguna acción positiva para desplegar la protección o eficacia de un derecho fundamental, de forma que, al menos, en principio, difícilmente se puede co-

6 STC 41/1981 FJ 1. La reciente reforma de la Ley Orgánica del Tribunal Constitucional (LO 6/2007, de 24 de mayo-BOE 25 mayo 2007) prevé una modificación procesal de este precepto para evitar una duplicidad de sentencias (una en amparo y otra de declaración de inconstitucionalidad) que había ocasionado alguna incoherencia en el pasado. Sobre la autocuestión de inconstitucionalidad, PIBERNAT DOMÉNECH, X., "El control de constitucionalidad en vía de recurso de amparo. El art. 55.2 LOTC y sus interpretaciones por el Tribunal Constitucional", RJC, 1983, núm. 3, pp. 153-168; URIAS MARTÍNEZ, J.P., La cuestión interna de inconstitucionalidad, McGraw-Hill, Madrid, 1996; MIERES MIERES, L.J., El incidente de constitucionalidad en los procesos constitucionales, Civitas, Madrid, 1998; PÉREZ TREMPS, P., "Comentario al art. 55 LOTC", en AAVV, Comentarios a la Ley Orgánica del Tribunal Constitucional, Tribunal Constitucional-Boletín Oficial del Estado, Madrid, 2001, pp. 868-877; URÍAS MARTÍNEZ, J. P., La tutela frente a leyes, CEPC, Madrid, 2001; ROIG BATALLA, A., "En torno al voto particular de la sentencia 18/1994, de 20 de enero. La autocuestión o el control sucesivo de constitucionalidad", REDC, 1995, núm. 44, pp. 299-322.

7 STC 113/1987 FJ 3 y STC 153/1988 FJ 2. En un caso concreto, el TC no puede constatar si un precepto del Código Penal infringe el art. $14 \mathrm{CE}$ (diferencias entre parejas de hecho y matrimonios), debido a que la sentencia del órgano judicial al aplicar el precepto no ha podido causar la referida lesión (STC 74/1997 FJ 2). En cualquier caso, el Tribunal Constitucional no admite que un recurso de amparo que solo puede tener como objeto la vulneración de un derecho fundamental, se pueda convertir en un recurso abstracto de inconstitucionalidad frente a preceptos legales (STC 122/1987 FJ 2). 
nectar a una lesión de un derecho fundamental sin un acto de aplicación previo por parte de los poderes aplicadores del Derecho que requiere una habilitación legal.

En relación con el legislador, el control sobre la vinculación positiva puede ser operativo en relación con la decisión normativa que estructura el contenido de las obligaciones positivas que debe realizar el poder público en materia de derechos fundamentales, o bien frente a la ausencia de dicha decisión, es decir, frente a la omisión legislativa de la articulación de las medidas. En cualquier caso, en principio no se puede decretar una inconstitucionalidad o una infracción de derechos fundamentales por ausencia de mecanismos de protección o de eficacia de los derechos fundamentales debido a que un procedimiento específico no está previsto de forma expresa en la Constitución. Por otra parte, la vía del art. 55.2 LOTC no puede permitir un control incidental en amparo de las decisiones legislativas en materia de vinculación positiva sin una gran carga argumental, ya que las acciones positivas de protección y dotación de eficacia difícilmente permiten derivar infracciones a los derechos fundamentales (proteger no es infringir), salvo que dichas medidas tengan como objeto la resolución de un conflicto entre derechos que implique la restricción de uno de ellos.

En definitiva, el control de la vinculación positiva del legislador a la Constitución opera sobre todo a partir del propio resultado legislativo, es decir, a partir de la adopción de una decisión normativa que incide en los derechos fundamentales a través de los procedimientos de declaración de inconstitucionalidad, con independencia de que el control sea abstracto o concreto, ya que un control de la abstención y omisión legislativa de un mandato constitucional no está previsto en nuestro ordenamiento. En cualquier caso, se debe tener en cuenta que la inactividad del legislador en último extremo y desde un punto de vista material solo puede ser solucionada a través de la adopción de las decisiones normativas previstas por el propio legislador, ya que el Tribunal Constitucional no puede sustituir al poder legislativo en las funciones exclusivas y propias que ejercen los órganos por mandato constitucional ${ }^{8}$.

No obstante, la inconstitucionalidad por omisión debería ser una pieza esencial en la primera fase de articulación del alcance de la vinculación positiva a los derechos fundamentales, pero solo se produce cuando una Constitución impone expresa o implícitamente al legislador la necesidad de dictar normas de desarrollo, en este caso de los derechos fundamentales, y el legislador no lo realiza dilatando en el tiempo la eficacia del mandato constitucional por la falta de adopción del acto normativo legislativo ${ }^{9}$, en este caso por falta de articulación de acciones positivas de protección o eficacia de los derechos fundamentales. La falta de previsión constitucional o legal del pro-

8 Sobre el control de las decisiones del legislador en materia de vinculación positiva en la doctrina alemana, DIETLEIN, J., Die Lebre von den grundrechtlichen Schutzpflichten, 2. Aufl., Berlin, Duncker \& Humblot, 2005, pp. 177 y ss.

9 STC 24/1982 FJ 3, STC 74/1987 FJ 4 y STC 87/1989 FJ 2 
cedimiento para el control de constitucionalidad de las omisiones legislativas conectadas a la vinculación positiva imposibilita un análisis formal de la materia ${ }^{10}$. De todas formas, se debe tener en cuenta que el Tribunal Constitucional ha admitido el amparo de los derechos fundamentales frente a omisiones legislativas ${ }^{11}$. Evidentemente, la consecuencia de una ausencia de regulación legislativa implica la aplicación directa de los derechos fundamentales en casos concretos, aunque con un contenido y alcance mínimo, limitado a la aplicación de las consecuencias constitucionales previstas ${ }^{12}$. De este modo, en las normas que tienen o son susceptible de generar una eficacia directa la omisión legislativa tiene una menor relevancia, ya que la omisión en si misma no vulnera la Constitución, sino el hecho de querer hacer valer dicha omisión para distorsionar la eficacia directa que despliega el precepto constitucional ${ }^{13}$. En consecuencia, se debe resaltar que jurisprudencialmente se trata de supuestos de protección directa de un derecho fundamental ante la ausencia de regulación normativa, no un supuesto ocasionado por no haber desarrollado o con un contenido ínfimo el deber de protección de los derechos fundamentales, es decir, la vinculación positiva en un caso concreto $^{14}$.

10 Sobre la inconstitucionalidad por omisión, VILLAVERDE MENÉNDEZ, I., La inconstitucionalidad por omisión, McGraw-Hill, Madrid, 1997; AHUMADA RUIZ, M.. ${ }^{a}$ Á., "El control de constitucionalidad de las omisiones legislativas", Revista del Centro de Estudios Constitucionales, 1991, núm. 8 (enero-abril), pp. 169-194; FERNÁNDEZ RODRÍGUEZ, J. J., La inconstitucionalidad por omisión: Teoria general, derecho comparado, el caso español, Civitas, Madrid, 1998; RUIZ MIGUEL, C., "Crítica de la llamada inconstitucionalidad por omisión", Revista de las Cortes Generales, 2000, núm. 51, pp. 117-134. Sobre el control de la omisión legislativa en materia de derechos fundamentales en la doctrina alemana, STERN, K., Das Staatsrecht der Bundesrepublik Deutschland. Bd. III/1, "Allgemeine Lehren der Grundrechte", C.H. Beck, München, 1988, pp. 1283 y ss.; JÜLICHER, F., Die Verfassungsbeschwerde gegen Urteile bei gesetzgeberischem Unterlassen. Zum Rechtsschutz bei gesetzgeberischem Unterlassen und willkürlichem gesetzlichen Begünstigungsausschluß, Duncker \& Humblot, Berlin, 1972; SEIWERTH, J., Zur Zulaessigkeit der Verfassungsbeschwerde gegenueber Grundrechtsverletzungen des Gesetzgebers durch Unterlassen, de Gruyter, Berlin, 1962.

11 Como ejemplo se puede utilizar la línea jurisprudencial de reconocimiento del derecho a efectuar emisiones de televisión local por cable, declarando nulas resoluciones administrativas que requerían el cese de dichas emisiones, ya que en el fondo implicaba la adopción de unos actos administrativos en ausencia de ley previa, lo que ocasionaba la aplicación preferente del derecho fundamental por aplicación directa de la norma constitucional que establecía el derecho fundamental (STC 31/1994, STC 47/1994, STC 98/1994, STC 281/1994 y STC 307/1994). En estos casos, se considera que la omisión de legislador de regular la televisión local por cable, dada la ausencia de la regulación legal de la concesión de dicha modalidad de televisión, no podía comportar pura y simplemente la prohibición de la actividad de difusión por parte de los particulares al ser un hecho contrario al art. 20.1 a y d CE (un resumen de la doctrina en STC 88/1995 FJ 6). Sobre el control en amparo de las omisiones del legislador, GÓMEZ AMIGO, L., La sentencia estimatoria del recurso de amparo, Aranzadi, Pamplona, 1998, pp. 199 y ss.

12 Por todas, STC 15/1982 FJ 8. Sobre los casos de omisiones legislativas vinculadas a derechos fundamentales y resueltos por aplicación directa a los derechos fundamentales, VILLAVERDE MENÉNDEZ, I., La inconstitucionalidad por omisión, op. cit., pp. 81 y ss.

13 Vid. VILLAVERDE MENÉNDEZ, I., La inconstitucionalidad por omisión, op. cit., p. 68.

14 No obstante, en ocasiones se ampara a pesar de la ausencia de normativa y se concreta por el Tribunal Constitucional el deber positivo de que la administración comunique la existencia de ficheros de personas y de las autoridades responsables de los mismos, así como los datos per- 
En general, se admite la distinción entre omisión absoluta que se plantea en el caso de que se produzca una ausencia completa de ley en una materia en la que la Constitución obliga a adoptar una decisión al legislador y la omisión parcial en la que una materia que debe ser regulada mediante ley por mandato constitucional explícito o implícito se cumple, pero cuyo contenido presenta una laguna o una insuficiencia normativa que imposibilita la plena efectividad y protección del mandato constitucional sobre todo en relación a un caso concreto ${ }^{15}$.

Dentro de esta diferencia en un sistema sin control directo de las omisiones legislativas, la posibilidad de control de omisiones absolutas no es admisible. Desde otra perspectiva, se debe tener en cuenta que la omisión parcial se puede interrelacionar directamente con la insuficiencia normativa en la 1 ley ${ }^{16}$, ya que implica una decisión incompleta, mal realizada o insuficientemente realizada por el legislador de la que se puede derivar un defecto de protección de los derechos fundamentales ${ }^{17}$. En estos supuestos cuando afecta a derechos fundamentales, en el caso de que se demuestre la existencia de un precepto legal omisivo, se podrá adoptar una declaración de inconstitucionalidad de carácter declarativo, sin nulidad. Esta sentencia puede producir unos efectos equivalentes a una sentencia de carácter interpretativo, que en la práctica supone, por una parte, la aplicación directa del precepto constitucional que establece el derecho fundamental en el caso de que sea posible en relación con el contenido omisivo y, por otra parte, la aplicación en el caso concreto de la ley en el contenido no omisivo de la misma.

En este contexto, se debe analizar brevemente la nueva reforma de la Ley Orgánica del Tribunal Constitucional recientemente aprobada, pero que ha variado sustancialmente el planteamiento originario, sobre todo en relación con este punto $^{18}$. En el proyecto inicial ${ }^{19}$, el precepto que se podía interrelacionar con el control de las leyes de articulación de la vinculación positiva a los derechos fundamentales era el art. 39.3 Proyecto LOTC, que establecía que cuando se declarara la inconstitucionalidad por "insuficiencia normativa" podía concederse un plazo al legislador para que actuara en consecuencia y, en el

sonales a los interesados (STC 254/1993 FJ 6 y 9). En este sentido, es posible deducir que los contenidos positivos de los derechos (facultad de solicitar información propia que afecte a la intimidad) no precisa desarrollo normativo (STC 254/1993 FJ 7).

15 Muy explícita es la distinción que realiza Villaverde entre omisión absoluta como silencio del legislador y omisión relativa como silencio de la ley. Vid. VILLAVERDE MENÉNDEZ, I., La inconstitucionalidad por omisión, op. cit., pp. 41 y ss.

16 Sobre las omisiones relativas, VILLAVERDE MENÉNDEZ, I., La inconstitucionalidad por omisión, op. cit., pp. 49 y ss.

17 ARANGO, R., El concepto de derechos sociales fundamentales, Legis, Bogota, 2005, pp. 184 y ss.

18 BOCG, Congreso de los Diputados, 25 noviembre 2005, Serie A, 60-1

19 De hecho en el informe de la ponencia se suprimieron todos los temas conectados a la nueva regulación de los efectos de las sentencias de inconstitucionalidad (vid. BOCG, Congreso de los Diputados, 5 diciembre 2006, Serie A, 60-9), por lo que estas reflexiones tendrán un mero valor teórico. 
caso de incumplimiento, el Tribunal Constitucional podía proceder para subsanar la insuficiencia.

En primer lugar, se debe insistir en la idea de que el precepto no se ha aprobado, pero podía haber mantenido unas relaciones directas con la vinculación positiva a los derechos fundamentales. En este sentido, el precepto en la redacción inicial no modifica el origen de la declaración de inconstitucionalidad que siempre debe tener como base una actividad, una decisión del legislador, por lo que la idea del control de una omisión legislativa absoluta y plena no era contemplada. Si que cabía interpretar e incluir en el concepto de insuficiencia normativa el control de la ley que estableciera una deficiente articulación de los instrumentos de vinculación positiva que puede ser motivado por causas materiales desde un punto de vista constitucional derivada de la insuficiencia de mecanismos de protección o de dotación de eficacia. No obstante, el supuesto más normal de aplicación hubiera sido el control de omisiones parciales en la articulación de la vinculación positiva, en el sentido de que sea necesario añadir mecanismos de protección o de dotación de eficacia por considerar el Tribunal Constitucional como insuficientes las decisiones del legislador en dichos ámbitos. Ahora bien, aunque no se puede deducir que este art. 39.3 Proyecto LOTC implicara la introducción de un control de las omisiones legislativas ${ }^{20}$, si que se podía interrelacionar con los mecanismos propios del control de constitucionalidad de las decisiones de articulación de la vinculación positiva que hubieran tenido alguna deficiencia de carácter omisivo en las mismas ${ }^{21}$. En cualquier caso, no se puede dejar de destacar que esta regulación encerraba necesariamente una comprensión material del concepto de insuficiencia normativa, que hubiera implicado como necesaria una decisión sustancial del Tribunal Constitucional, es decir, una sentencia que se integraría en los supuestos de activismo o de legislador positivo en el caso de que se subsanara dicha insuficiencia ${ }^{22}$. La falta de una previsión de los efectos de esta declaración de inconstitucionalidad por insuficiencia normativa ha hecho aconsejable suprimir este supuesto de momento en la tramitación parlamentaria, del que tampoco han sido ajenas las críticas doctrinales planteadas ${ }^{23}$, aunque desde un punto de vista material no se escapa la posibilidad de utilización para controlar decisiones del legislador en materia de vinculación positiva a los derechos fundamentales.

20 En dicho sentido, CARRILLO, M., en AAVV, "Encuesta sobre la reforma de la Ley Orgánica del Tribunal Constitucional", Teoría y Realidad Constitucional, 2006, núm. 18, p. 63.

21 De todos modos no se entra a valorar en este trabajo aspectos técnicos en la redacción del proyecto que pueden considerarse deficientes, vid. GARRORENA, A., en AAVV, "Encuesta sobre la reforma de la Ley Orgánica del Tribunal Constitucional", op. cit., pp. 66-67.

$22 \mathrm{El}$ concepto de insuficiencia normativa puede ser interpretado de un modo formal (insuficiencia de fuerza de ley) o material que necesariamente implicará la inconstitucionalidad de una norma en base a lo que omite. Vid. FERNÁNDEZ FARRERES, G., "Comentario al anteproyecto de la Ley Orgánica del Tribunal Constitucional, hecho público en septiembre 2005", en AAVV, La reforma de la justicia constitucional, Aranzadi, Cizur Menor, 2006, pp. 48-49.

23 Por todos, FERNÁNDEZ FARRERES, G., op. cit., p. 50, aunque en la encuesta y debate publicado en el mencionado libro aparecen otras muchas. 
En este sentido, el supuesto más ordinario de la aplicación de la insuficiencia de la necesidad de protección de la ley puede derivar de la protección constitucional en amparo, ya que en el caso del poder ejecutivo y judicial se controla los efectos de la protección de los derechos fundamentales en el ejercicio de las respectivas funciones, incluso las omisiones, y no solo a partir del resultado de la actividad, en el acto normativo concreto realizado tal como sucede con el legislador. En consecuencia, la omisión de la ley puede derivar, ya que se están ante una laguna jurídica, en una protección no efectiva realizada por el poder judicial, debido a la obligación de la aplicación directa de los derechos fundamentales en caso de ausencia normativa de desarrollo de los derechos fundamentales. Si interpretativamente se puede incluir una acción o contenido positivo en los derechos fundamentales, el poder judicial debe reconocerlo e incluirlo en el caso concreto sin renunciar a su protección. En caso contrario, el poder judicial será el responsable de la infracción del derecho fundamental, de forma que eventualmente el Tribunal Constitucional incluya en el ámbito de protección un contenido positivo en los derechos fundamentales, que generará un precedente constitucional vinculante en futuras decisiones judiciales sobre la materia.

El Tribunal Constitucional frecuentemente ha desarrollado un sentido institucional al utilizar pronunciamientos de advertencia al legislador en supuestos de insuficiencia normativa, pero sin extraer evidentemente consecuencias de declaración de inconstitucionalidad que pueden agravar los defectos de una disposición legal y potenciar la falta de certeza y seguridad jurídica. Cuando la insuficiencia normativa es de carácter parcial, se advierte su existencia, pero se deja intacta la habilitación legal para la aplicación de la restricción de un derecho fundamental en otros supuestos correctos desde un punto de vista constitucional, evitando de esta forma un vacío normativo. En estos casos, la sentencia del Tribunal Constitucional al mismo tiempo que constata la existencia de la insuficiencia normativa advirtiendo de la misma al legislador, declara la protección del derecho fundamental en el caso concreto que genera un precedente aplicable en el futuro por el propio Tribunal Constitucional y por la jurisdicción ordinaria, pero en el fondo dicha doctrina solo es un recordatorio de que el legislador debe configurar nuevos procesos legales que adopten habilitaciones legales añadidas en el plazo más breve ${ }^{24}$. Por otra parte, conviene recordar que las omisiones legislativas que produzcan una infracción de un derecho fundamental puede ser objeto de control por parte del TEDH, cuya jurisprudencia es asumida por el Tribunal Constitucional como criterio de resolución de futuros conflictos. Esta jurisprudencia sin llegar a ser sustitutiva del legislador, ni autorizadora de una actuación positiva directa de la jurisdicción ordinaria, si que es un cauce para fijar criterios mate-

24 Por todas STC 184/2003 FJ 7. Con anterioridad se producen antecedentes de pronunciamientos del Tribunal Constitucional en que advierte al legislador de la necesidad de una corrección legislativa por insuficiencia, STC 96/1996 FJ 23, STC 235/1999 FJ 13. 
riales de resolución de ponderaciones judiciales necesarias frente a lagunas legislativas que deben ser resueltas mediante aplicación directa de los derechos fundamentales. Las insuficiencias normativas o de calidad legislativas declaradas por el TEDH tienen consecuencias y posibilidades de control una vez asumidas por el Tribunal Constitucional y aplicadas con posterioridad por los tribunales ordinarios.

En el fondo la sentencia que constata la existencia de la insuficiencia normativa tiene carácter meramente declarativo como advertencia o puesta en conocimiento de forma expresa al legislador del problema que presenta su normativa y de las consecuencias que puede tener este hecho en los posibles procesos de aplicación por la jurisdicción ordinaria en el caso de que no proceda a la corrección de su normativa. En esencia, esta sentencia declarativa en caso de insuficiencia normativa se puede caracterizar como un diálogo institucionalizado entre el Tribunal Constitucional y el legislador, pero no se puede derivar de ella un efecto constitutivo semejante al de las sentencias declarativas de inconstitucionalidad como nulidad radical.

En la doctrina alemana, para el control de la insuficiencia normativa se ha desarrollado el principio de la prohibición de defecto de protección o infraprotección de los derechos fundamentales (Untermassverbot). Esta prohibición de defecto de protección se contrapone a la clásica prohibición de exceso de restricción de un derecho fundamental (Übermassverbot) que es una de las formulaciones con las que se conoce la aplicación del principio de proporcionalidad en sentido amplio para el control de las decisiones restrictivas del legislador en materia de derechos fundamentales ${ }^{25}$. A nuestros efectos es conveniente recordar que el principio de proporcionalidad no era aplicable en

25 Sobre la prohibición de exceso, un resumen actual en la Ley Fundamental de Bonn, en STERN, K., Das Staatsrecht der Bundesrepublik Deutschland. Bd. III/2 "Allgemeine Lebren der Grundrechte", C.H. Beck, München, 1994, PP. 761 y ss. La prohibición de exceso (Übermassverbot) fue la terminología utilizada mayoritariamente durante los años 50 y 60, para referirse al principio de proporcionalidad, que fue el término de uso generalizado en la doctrina alemana a partir de los años ochenta, a pesar de que ambos términos se siguen utilizando indistintamente en todas las épocas. La referencia clásica al tema de la prohibición de exceso se debe a P. Lerche (LERCHE, P., Übermass und Verfassungsrecht. Zur Bindung des Gesetzgebers an die Grundsätze der Verhältnismässigkeit und der Erforderlichkeit, Carl Heymanns Verlag, Köln, Berlin, München, Bonn, 1961). Sobre el origen de la prohibición de defecto de protección, vid. MAYER, M., Untermaß, Übermaß und Wesensgehaltgarantie. Die Bedeutung staatlicher Schutzpflichten für den Gestaltungsspielraum des Gesetzgebers im Grundrechtsbereich, Nomos, Baden-Baden, 2005, pp. 63-64 y TZEMOS, V., Das Übermassverbot, Peter Lang, Frankfurt, 2004, pp. 4 y ss. El origen dogmático del concepto se encuentra en la obra de CANARIS, C.W., "Grundrechte und Privatrecht", $A c P, 1984$, Bd. 184, pp. 200 y ss., en concreto, p. 228. De este mismo autor, más recientemente, sobre los efectos debilitados de la función de protección de los derechos y la prohibición de defecto de protección, CANARIS, Cl.-W., Grundrechte und Privatrecht. Eine Zwischenbilanz, Walter de Gruyter, Berlin, 1999, pp. 43 y ss. En general, sobre la prohibición de defecto de protección en los derechos fundamentales en el ámbito del Derecho privado, RUFFERT, M., Vorrang der Verfassung und Eigenständigkeit des Privatrechts. Eine verfassungsrechtliche Untersuchung zur Privatrechtswirkung des Grundgesetzes, Mohr Siebeck, Tübingen, 2001, pp. 215 y ss. 
supuestos de configuración normativa de los derechos fundamentales, ya que por definición requiere su aplicación a restricciones para poder ser operativo. En cambio, la prohibición de defecto de protección es aplicable en esencia para el control de la actividad de configuración de los derechos fundamentales, para determinar las distorsiones o insuficiencias en la protección de los derechos fundamentales decidida por el legislador ${ }^{26}$. En nuestro ordenamiento, tanto la prohibición de exceso de restricción como la prohibición de defecto de protección son susceptibles de integrarse en la interdicción de arbitrariedad de las decisiones legislativas previstas en el art. 9.3 CE, con la consecuencia de que su contenido y controles materiales forman parte de los parámetros del control de constitucionalidad sin necesidad de articular un procedimiento específico.

Desde un punto de vista material, la principal problemática que plantea la reserva de ley en materia de derechos se relaciona con el contenido material y funcional de las leyes de desarrollo de los derechos fundamentales. En este sentido, el Tribunal Constitucional ha señalado que desarrollo significa la regulación de un derecho fundamental o de una libertad pública que desarrolle la Constitución de manera directa y en elementos esenciales para la definición del derecho fundamental, ya sea en una regulación directa, general y global del mismo o en una parcial o sectorial, pero, igualmente, relativa a aspectos esenciales del derecho, y no, por parcial, menos directa o encaminada a contribuir a la delimitación y definición legal del derecho ${ }^{27}$. De este modo, desde un punto de vista material, el Tribunal ha afirmado que lo que está reservado a la Ley Orgánica es la regulación de determinados aspectos esenciales para la definición del derecho, la previsión de su ámbito y la fijación de sus límites en relación con otras libertades constitucionalmente protegidas ${ }^{28}$. En definitiva, el Tribunal efectúa una doble referencia, por una parte, a los aspectos esenciales conectados a la definición o previsión del ámbito de los derechos y, por otra, al establecimiento de restricciones o límites a los derechos.

26 Sobre la prohibición de defecto o insuficiencia de protección la doctrina alemana es amplia, UNRUH, P., Zur Dogmatik der grundrechtlichen Schutzpflichten, Berlin, Duncker \& Humblot, 1996, pp. 151-152; LINDNER, J. F., Theorie der Grundrechtsdogmatik, Tübingen, Mohr Siebeck, 2005, pp. 512 y ss.; DIETLEIN, J., Die Lebre von den grundrechtlichen Schutzpflichten, op. cit., pp. II-III (introducción); DOLDERER, M., Objektive Grundrechtsgehalte, Berlin, Duncker \& Humblot, 2000, PP. 271 y ss.; KRINGS, G., Grund und Grenzen grundrechtlicher Schutzansprüche. Die subjektiv-rechtliche Rekonstruktion der grundrechtlichen Schutzpflichten und ihre Auswirkung auf die verfassungsrechtliche Fundierung des Verbrauchervertragsrechts, Duncker \& Humblot, Berlin, 2003, pp. 297 y ss.; CREMER, W., Freiheitsgrundrechte. Funktionen und Strukturen, Mohr Siebeck, Tübingen, 2003, pp. 320 y ss. No obstante, desarrollan una postura más crítica, UNRUH, P., Zur Dogmatik der grundrechtlichen Schutzpflichten, Berlin, Duncker \& Humblot, 1996, pp. 83 y ss.; GELLERMANN, M., Grundrechte in einfachgesetzlichem Gewande. Untersuchung zur normativen Ausgestaltung der Freiheitsrechte, Tübingen, Mohr Siebeck, 2000, pp. 342 y ss. En la doctrina española, un resumen del planteamiento en DOMÉNECH PASCUAL, G., Derechos fundamentales y riesgos tecnológicos, Centro de Estudios Políticos y Constitucionales, Madrid, 2006, pp. 163 y ss. 27 STC 67/1985 FJ 5, STC 140/1986 FJ 5, STC 160/1987 FJ 2, STC 173/1998 FJ 7

28 STC 140/1986 FJ 5, STC 160/1986 FJ 4, STC 101/1991 FJ 2, STC 88/1995, STC 173/1998 FJ 7. 
En consecuencia, el contenido material de las leyes de desarrollo de los derechos fundamentales puede basarse en las actividades de intervención en el derecho fundamental, entendida como una modificación restrictiva no contraria a la Constitución de alguno de los elementos configuradores de los derechos fundamentales (titular, destinatario y objeto) con la finalidad de que no forme parte del contenido y ejercicio del derecho, hasta la configuración del derecho fundamental, entendida como dotación del contenido de alguno de los elementos configuradores de los derechos fundamentales para facilitar su ejercicio del derecho fundamental. En cualquier caso, en relación con estas dos funciones materiales de la reserva de ley en materia de derechos fundamentales, la limitación y la configuración de los derechos fundamentales, se debe tener en cuenta que la dimensión objetiva de los derechos fundamentales ha desarrollado un efecto trasversal que dificulta una diferenciación analítica entre ambos supuestos ${ }^{29}$.

En este sentido, la vinculación positiva a los derechos fundamentales se integra como parte de la decisión legislativa de desarrollo de los derechos fundamentales, pudiendo formar parte de sus consecuencias jurídicas las distintas obligaciones y acciones que debe ejercer el poder público de forma directa en el ámbito de la protección del derecho fundamental, de modo que se le podría aplicar a dichos componentes todas las garantías derivadas de la Constitución como el amparo.

En relación a la configuración jurídica de los derechos fundamentales se parte de la premisa dogmática de que no tiene el rango constitucional de un derecho fundamental, pero en la medida en que la regulación legal es un presupuesto necesario para el ejercicio del derecho fundamental se le tiene que proporcionar la protección material que tendría el derecho fundamental. En consecuencia, a efectos de control de constitucionalidad no puede ser utilizada la configuración jurídica como objeto procesal de los mismos, pero al determinar el contenido prescriptivo de los derechos fundamentales puede ser protegida dicha configuración jurídica a través del procedimiento de amparo, cuyo objeto procesal debe ser protegido de forma plena y no solo a través del contenido constitucional estricto ${ }^{30}$. En la medida que los instrumentos de vinculación positiva se integran en esta primera función de la configuración de los derechos fundamentales, también supondrá la integración de sus efectos y consecuencias en su protección en amparo.

29 CORNILS, M., Die Ausgestaltung der Grundrechte. Untersuchungen zur Grundrechtsbindung des Ausgestaltungsgesetzgebers, Tübingen, Mohr Siebeck, 2005, pp. 567 y ss. No obstante, parte de la doctrina alemana que se puede diferenciar entre la intervención que afecta al aspecto subjetivo o a la protección negativa de los derechos fundamentales y la configuración que afectaría a los contenidos objetivos de los derechos fundamentales. Vid. GELLERMANN, M., Grundrechte in einfachgesetzlichem Gewande, op. cit., pp. 50 y ss.

30 En este sentido, el contenido adicional del derecho a la libertad sindical establecido mediante ley puede considerarse objeto de protección en amparo, aunque el Tribunal Constitucional ha afirmado que no le corresponde controlar la interpretación de la ley, sino valorar dicha interpretación desde una perspectiva constitucional (STC 61/1989 FJ 2). 


\section{LA VINCULACIÓN POSITIVA DE CARÁCTER SUBJETIVO DEL PODER EJECUTIVO}

La vinculación positiva del poder ejecutivo a los derechos fundamentales precisa su estructuración previa a través de la ley, de forma que no cabe ni tiene la posibilidad de articular decisiones autónomas que impliquen la determinación de acciones de protección o dotación de eficacia, decididas directamente por cualquier administración o poder ejecutivo. En materia de derechos fundamentales, el poder ejecutivo es un órgano subordinado a la ley, ya que cualquier tipo de acto administrativo precisa una previa habilitación legislativa ${ }^{31}$.

El art. 43.1 LOTC establece un objeto considerablemente amplio para la modalidad de recurso de amparo dedicada al control del poder ejecutivo y de la administración en materia de derechos, al aludir a tres categorías distintas de actos o situaciones a controlar: disposiciones, actos jurídicos y simples vías de hecho ${ }^{32}$. En términos de vinculación positiva, es importante determinar que puede ser objeto del recurso cualquier actuación realizada por un órgano de la Administración, pero también la inactividad, es decir, la pasividad y el silencio ilegítimos del órgano administrativo que produzca una infracción en el derecho fundamental ${ }^{33}$. El Tribunal Constitucional ha afirmado que la administración no puede beneficiarse por el incumplimiento de una obligación de resolver expresamente al no dar respuesta a solicitudes y peticiones de los ciudadanos, ni tampoco de su incompetencia forzando a acudir a los tribunales para la resolución de las mismas ${ }^{34}$.

No obstante, no había un reconocimiento expreso en la LOTC del control de las omisiones del ejecutivo y la administración en materia de derechos fun-

$31 \mathrm{El}$ Tribunal Constitucional ha afirmado que la integridad de los derechos fundamentales no puede quedar a la discrecionalidad unilateral de las Administraciones Públicas (STC 50/1995 FJ 7). Sobre las consecuencias del principio de legalidad en la actuación administrativa en materia de derechos fundamentales, a partir del principio de reserva de ley y de jerarquía de la ley sobre la actuación administrativa, HORN, H.-D., Die grundrechtsunmittelbare Verwaltung. Zur Dogmatik des Verhältnisses zwischen Gesetz, Verwaltung und Individuum unter dem Grundgesetz, Mohr Siebeck, Tübingen, 1999, pp. 21 y ss. Sobre la vinculación positiva del ejecutivo a la ley, GARRORENA MORALES, A., El lugar de la Ley en la Constitución española, CEC, Madrid, 1980, pp. 78 y ss.

32 Sobre el amparo constitucional, FERNÁNDEZ FARRERES, G., El recurso de amparo según la jurisprudencia constitucional, Madrid, 1994; AAVV, La sentencia de amparo constitucional, CEC, Madrid, 1996. En concreto sobre la subsidiariedad, BORRAJO INIESTA, I.-DÍEZ-PICAZO JIMÉNEZ, I.-FERNÁNDEZ FARRERES, G., El derecho a la tutela judicial y el recurso de amparo. Una reflexión sobre la jurisprudencia constitucional, Civitas, Madrid, 1995, P. 119 y ss.; DÍEZ-PICAZO GIMÉNEZ, I., "El artículo 53.2 de la Constitución: interpretación y alternativas de desarrollo", en DE LA OLIVA SANTOS, A.-DÍEZ-PICAZO GIMÉNEZ, I., Tribunal Constitucional, jurisdicción ordinaria y derechos fundamentales, McGraw-Hill, Madrid, 1996; OLIVER ARAUJO, J., El recurso de amparo, Universidad de las Islas Baleares, Palma de Mallorca, 1986; PÉREZ TREMPS, P., El recurso de amparo, Tirant lo blanch, Valencia, 2004

33 En general, sobre el amparo frente a la inactividad de la administración, vid. SÁNCHEZ MORÓN, M., "Comentarios al art. 43 LOTC", en REQUEJO PAGÉS, J. L. (coord.), Comentarios a la Ley Orgánica del Tribunal Constitucional, op. cit., pp. 687-688.

34 STC 6/1986 FJ 3, STC 180/1991 FJ 1, STC 254/1993 FJ 3 
damentales, a diferencia de lo preceptuado sobre las omisiones judiciales (art. 44 LOTC). Esta situación ha variado de forma expresa tras la reciente reforma de la LOTC, ya que incluye en los nuevos art. 41.2 y 43 LOTC dentro de los objetos de amparo frente a actos de los órganos administrativos de una forma expresa a las omisiones administrativas ${ }^{35}$. Sin embargo, siempre fue posible plantear la vía preferente y sumaria de protección de los derechos fundamentales para una tutela jurisdiccional ante casos de silencio administrativo. Por otra parte, también los art. 31 y 32 LJCA protegen aquellas pretensiones judiciales con las se aspira a reparar la obstrucción del ejercicio de derechos fundamentales, originadas por la falta de reconocimiento de una situación jurídica individualizada o la inactividad de la Administración Pública.

En este sentido, dejando al margen las consecuencias de la reforma de la LOTC, lo cierto es que las omisiones de los órganos administrativos que causen una infracción de derechos fundamentales son controlables por la jurisdicción ordinaria, con independencia de que se considere objeto del amparo previsto en el art. 43 LOTC $^{36}$. A partir de dicha resolución judicial el amparo constitucional siempre es posible, ya que aunque no fuera admisible frente a las omisiones administrativas, si que se puede revisar la decisión judicial, ya que si no protege el derecho fundamental en caso de que debiera, se convierte al órgano judicial en infractor de dicho derecho. Esta técnica de protección indirecta en amparo es similar a la que se utiliza en casos de eficacia de los derechos frente a terceras personas (Drittwirkung), es decir, infiere a la decisión judicial la infracción del derecho fundamental en supuestos de violación de derechos producida por la falta de acción de los órganos administrativos que no ha sido debidamente controlada en el proceso judicial. En este sentido, se debe recordar que el art. 29 LJCA permite el control ante la jurisdicción ordinaria contencioso-administrativa de cualquier decisión conectada a la vinculación positiva de los derechos fundamentales, ya que se puede dirigir contra la administración para que sea obligada a realizar una prestación concreta, cuando sea deducible de una disposición general que no precisa de actos de aplicación o bien directamente de un acto de aplicación, incluso permitiendo la ejecución de los actos firmes.

Desde otra perspectiva, en este punto, se debe recordar y partir de la idea de que en los sistemas parlamentarios la actividad del poder ejecutivo no se limita exclusivamente a la ejecución de la ley. Si bien la ley es un factor de determinación decisivo para la actividad y funciones del poder ejecutivo y que la vinculación a los derechos fundamentales se produce mediante la aplicación del principio de legalidad de la Administración, de forma que la

35 Sobre la introducción en la reforma de la LOTC de las omisiones administrativas como objeto del recurso de amparo frente a actos administrativos, vid. ESPÍN TEMPLADO, E., "Comentarios al anteproyecto de reforma de la LOTC", en AAVV, La reforma de la justicia constitucional, Aranzadi, Cizur Menor, 2006, p. 26.

36 Sobre las omisiones como objeto del amparo frente a actos administrativos, OLIVER ARAUJO, J., El recurso de amparo, op. cit., pp. 185 y ss. 
mayoría de sus acciones relacionadas con los derechos fundamentales y en particular con la vinculación positiva se deben considerar integradas dentro del ámbito de la actividad reglada, al mismo tiempo se debe examinar la apertura que realiza la normativa de desarrollo de los derechos fundamentales para adoptar comportamientos flexibles del poder ejecutivo que pueden dar lugar a una actividad discrecional relacionada con los derechos fundamentales.

Un mero análisis de los supuestos permite distinguir entre actuaciones administrativas directamente habilitadas por la ley con carácter general para el ejercicio de funciones de seguridad pública o con carácter específico vinculado a algún derecho fundamental concreto y actuaciones que precisa con carácter previo a su realización de una autorización judicial específica ${ }^{37}$. Estas medidas pueden ser de carácter preventivo y de carácter represivo ${ }^{38}$. Las medidas de carácter preventivo implican intervenciones administrativas dirigidas a impedir el ejercicio de derechos fundamentales con anterioridad a que se cometa un perjuicio en el derecho fundamental, pero se caracterizan porque generalmente se autoriza legislativamente de modo directo la intervención sin necesidad de mediación judicial. Estas medidas preventivas pueden tener efecto general cuando se plantean sin estar específicamente relacionada con un derecho fundamental concreto, o tener efecto especial, es decir, cuando son medidas específicamente relacionadas con un derecho fundamental concreto. Las medidas de carácter represivo implican una intervención administrativa o judicial con posterioridad al ejercicio del derecho fundamental dirigidas a corregir el perjuicio o infracción cometida mediante un ejercicio ilegal o inconstitucional de un derecho fundamental. Cuando se habilita la intervención administrativa mediante medidas represivas frecuentemente requiere a su vez una previa autorización judicial para la ejecución de la medida. En general, las medidas de intervención administrativa en materia de derechos fundamentales tienen una tendencia natural a situarse entre las medidas de carácter preventivo, salvo que se tengan funciones de control adoptadas por administraciones independientes.

En la vinculación del poder ejecutivo a los derechos fundamentales, se debe tener en cuenta el reconocimiento de ámbitos en los que se produce una apertura para la valoración de las circunstancias concretas del caso que permita un espacio de discrecionalidad de decisión al poder ejecutivo, siendo los más importantes la utilización e integración de los conceptos jurídicos indeterminados previstos por la ley en la actuación administrativa generalmen-

37 Sobre las decisiones generales incluidas en la actividad policial vinculada a la seguridad pública, BENFER, J., Rechtseingriffe von Polizei und Staatsanwaltschaft. Voraussetzungen und Grenzen, 3. Aufl., München, Beck, 2005, pp. 35 y ss., en concreto sobre la necesidad de autorización judicial, pp. 37 y ss.

38 En la doctrina alemana, sobre la distinción entre medidas preventivas y represivas vinculadas a la actuación administrativa en materia de derechos fundamentales, BENFER, J., Rechtseingriffe von Polizei und Staatsanwaltschaft. Voraussetzungen und Grenzen, op. cit., pp. 4 y ss. En la doctrina austriaca, HOLOUBEK, M., Grundrechtliche Gewährleistungspflichten. Ein Beitrag zu einer allgemeinen Grundrechtsdogmatik, Springer, Wien [u.a.], 1997, pp. 267 y ss. 
te vinculados a la aplicación de límites a los derechos fundamentales como el orden público y los ámbitos de estricta actividad discrecional en la medida que estén interrelacionados con la vinculación positiva a los derechos fundamentales ${ }^{39}$. En ocasiones, esta actuación administrativa es una consecuencia de la articulación de una administración independiente creada con la finalidad de proteger y garantizar los derechos fundamentales, tal como sucede con las Agencias de Protección de Datos o el Consejo del Audiovisual de Cataluña.

En cualquier caso, se debe tener en cuenta el alcance de la prohibición de arbitrariedad (art. 9.3 CE), que entre otros supuestos prohíbe que la administración adopte decisiones para seleccionar o elegir a los administrados a los aplica o no una normativa vigente ${ }^{40}$, pero sobre todo prohíbe que se pueda utilizar uno de estos ámbitos de decisión administrativa discrecional sin una justificación o motivación de las razones de su decisión, es decir, se permite una libre valoración de las circunstancias concretas del caso, pero no una ausencia plena de justificación en la decisión de la administración ${ }^{41}$.

La motivación de los actos administrativos implica la obligación de expresar las cualidades de la decisión incluyendo las razones materiales y jurídicas que le sirve de soporte y base, lo que permitirá la protección frente a las decisiones incorrectas, por el mero hecho de constar por escrito dichas razones se posibilita un aumento de las razones persuasivas de su corrección y mejora la aceptación por los ciudadanos que tienen la posibilidad de conocer dicha argumentación y, finalmente, mejora la posibilidad de realizar un control posterior por otras órganos administrativos o externos o de carácter judicial a cerca de la decisión adoptada ${ }^{42}$. Estas funciones y razones permite deducir que los controles fundamentales sobre las actividades de vinculación positiva desarrollas por el poder ejecutivo recaerán sobre todo en el alcance material y formal de la motivación de sus resoluciones.

Los conceptos jurídicos indeterminados se suelen aplicar en materia de derechos fundamentales, como en otros ámbitos, en su función de la necesidad de medidas de libre valoración de la administración para determinar un correcto ejercicio de los derechos fundamentales ${ }^{43}$, interrelacionándose di-

39 En general, sobre el ámbito de la actuación discrecional de la administración en la doctrina alemana, PACHE, E., Tatbestandliche Abwägung und Beurteilungsspielraum. Zur Einheitlichkeit administrativer Entscheidungsfreiräume und zu deren Konsequenzen im verwaltungsgerichtlichen Verfahren; Versuch einer Modernisierung, Mohr Siebeck, Tübingen, 2001, pp. 11 y ss.

40 STC 151/1986 FJ 6

41 Sobre la obligación de motivación de los actos y decisiones administrativas en la doctrina alemana, KISCHEL, U., Die Begründung, op. cit., pp. 222 y ss. Sobre el contenido y la function de la obligación de motivación de los actos administrativos, EISENBERG, E., Die Anhörung des Bürgers im Verwaltungsverfahren und die Begründungspflicht für Verwaltungsakte. Rechtsvergleichende Untersuchung zweier zentraler Grundsätze des Verwaltungsverfahrens in Deutschland und Frankreich, Nomos-Verl.-Ges., Baden-Baden, 1999, pp. 190 y ss.

42 EISENBERG, E., Die Anhörung des Bürgers im Verwaltungsverfahren und die Begründungspflicht für Verwaltungsakte, op. cit., pp. 49-56.

43 Sobre la vinculación a los derechos fundamentales en el caso de los conceptos jurídicos indeterminados, STERN, K., Das Staatsrecht der Bundesrepublik Deutschland. Bd. III/1, op. cit, pp. 1352 y ss. 
rectamente con la actividad discrecional de la administración ${ }^{44}$. No obstante, a pesar de que tradicionalmente en la doctrina alemana se tenía una tendencia a separar y diferenciar los conceptos jurídicos indeterminados y la actividad discrecional de la administración ${ }^{45}$, lo cierto es que la discrecionalidad de la administración recae en conceptos jurídicos indeterminados frecuentemente, como consecuencia de una decisión legislativa de conceder un espacio a la libre valoración, sin que signifique que se estructura unas habilitaciones exentas de control en la determinación y ejercicio de la actividad autorizada, lo que ha facilitado la defensa de las denominadas teorías de la unidad que consideran que la estructura, consecuencias y control de ambos institutos jurídicos, conceptos jurídicos indeterminados y actividad discrecional de la administración son idénticos ${ }^{46}$.

En relación con la actuación discrecional del ejecutivo en materia de derechos fundamentales, se puede buscar una interrelación global en el principio de igualdad en la aplicación de la ley a partir del tratamiento por parte de la administración y en el respeto y virtualidad del precedente administrativo ${ }^{47}$. En este sentido, la discrecionalidad establecida por ley que estructura la vinculación positiva a los derechos fundamentales se debe aplicar de igual modo en relación con cualquier ciudadano ${ }^{48}$. Por este motivo, su control se debe articular a través de mecanismos de autovinculación de la administración basados en la protección de la confianza y la seguridad jurídica con el principio de que no se puede ir contra los propios actos y en la vinculación al precedente administrativo ${ }^{49}$.

La existencia de una mayor o menor ámbito de actuación discrecional en materia de derechos depende de la intensidad de regulación del legislador en materia de autorización de la actividad administrativa relacionada con los derechos fundamentales. Siempre se tiene que tener presente que la actividad

44 Sobre los conceptos jurídicos indeterminados y su relación con la actividad discrecional de la administración, JESCH, D., "Unbestimtes Rechtsbegriff und remesen in rechtstheoretischer und verfassungsrechtslicher Sicht", $A O ̈ R, 1957$, vol. 82, pp. 163 y ss. en especial, pp. 211 y ss. En la doctrina española, sobre la relación entre actos discrecionales y conceptos jurídicos indeterminados, BARTOLOMÉ CENZANO, J.C. de, El orden público como límite al ejercicio de los derechos y libertades, Centro de Estudios Políticos y Constitucionales, Madrid, 2002, pp. 72 y ss.; BELTRÁN DE FELIPE, M., Discrecionalidad administrativa y Constitución, Tecnos, Madrid, 1995, pp. 38 y ss.

45 Sobre la distinción tradicional, PACHE, E., Tatbestandliche Abwägung und Beurteilungsspielraum, op. cit., pp. 57-63.

46 Sobre la teoría de la unidad, PACHE, E., Tatbestandliche Abwägung und Beurteilungsspielraum, op. cit., pp. 108 y ss.

47 Sobre el significado del principio de igualdad para el control de la actividad discrecional de la administración, STERN, K., Das Staatsrecht der Bundesrepublik Deutschland. Bd. III/1, op. cit,. pp. 1356 y ss.

48 Sobre la influencia de la vinculación positiva en la actividad discrecional de la administración, DIETLEIN, J., Die Lehre von den grundrechtlichen Schutzpflichten, op. cit., pp. 187 y ss.

49 Sobre el ámbito discrecional de la administración y su vinculación a los derechos fundamentales, STERN, K., Das Staatsrecht der Bundesrepublik Deutschland. Bd. III/1, op. cit, . pp. 1354 y ss. 
reglada está contrapuesta a la actividad discrecional. Teóricamente en materia de derechos fundamentales debería de aplicarse con mayor rigor la actividad reglada en el sentido de que el legislador debe fijar la mayor parte de los elementos que determinar la incidencia en los derechos fundamentales, dejando el menor espacio posible para la decisión discrecional de la administración, que en todo caso no puede considerase en abstracto excluida del ámbito de los derechos fundamentales. Ahora bien, esta actividad discrecional se debe relacionar para la fijación de los elementos fácticos y la decisión y valoración de las circunstancias del caso concreto, pero sin que tenga competencia para configurar los elementos esenciales relacionados con el derecho fundamental.

El principal instrumento de control de la actividad discrecional de la administración cuando afecta a los derechos fundamentales es la motivación del acto administrativo adoptado como consecuencia de la autorización de incidencia en el derecho fundamental concreto. La exposición de las razones para la adopción del acto administrativo de forma externa implica la necesidad de una concreción de la ponderación y valoración del derecho fundamental en el caso concreto ${ }^{50}$. En cualquier caso, el control judicial sobre la ponderación realizada por la administración en materia de derechos fundamentales debe recaer sobre la utilización de la competencia subjetiva y objetiva establecida por la norma autorizante de la actividad administrativa, la existencia y suficiencia de una motivación de la adopción del acto administrativo en la que se valore específicamente el derecho fundamental afectado, así como su coherencia interna y plenitud desde un punto de vista formal y material y, finalmente, la utilización de un criterio de comparación y diferenciación en relación a otras decisiones similares en casos análogos ${ }^{51}$.

\section{LA VINCULACIÓN POSITIVA DEL PODER JUDICIAL A LOS DERECHOS FUNDAMENTALES}

La vinculación del poder judicial a los derechos fundamentales se articula sobre todo en base a su función de control del poder ejecutivo tanto de sus disposiciones reglamentarias como de la legalidad de cualquier actuación administrativa (art. 6 y 8 LOPJ) y a su papel de protección general de los derechos fundamentales que permite deducir su vinculación íntegra con la finalidad de garantizar la tutela efectiva (art. 7.1 LOPJ), así como la obligación de aplicación del contenido constitucionalmente declarado de los derechos

50 Sobre la ponderación como instrumento de contraposición de la actividad discrecional y su significado, PACHE, E., Tatbestandliche Abwägung und Beurteilungsspielraum, op. cit., pp. 479 y ss.

51 Sobre el control judicial de la ponderación y motivación de la actividad discrecional administrativa, PACHE, E., Tatbestandliche Abwägung und Beurteilungsspielraum, op. cit., pp. 495 y ss. En general, sobre el control de la actividad discrecional administrativa en la doctrina alemana, HUMMEL, H., Gerichtsschutz gegen Prüfungsbewertungen. Rechtsweggarantie, rechtliches Gebör, Beurteilungsspielraum, Duncker \& Humblot, Berlin, 1969, pp. 15 y ss. 
fundamentales, sin que sea admisible que se pueda restringir, menoscabar o inaplicar (art. 7.2 LOPJ). En consecuencia, si es deducible cualquier obligación o deber positivo estructurado mediante ley que deba realizar el poder judicial en materia de derechos, la inactividad o falta de adecuación a la previsión sería equivalente a una infracción de los derechos fundamentales a los que afectara. La fórmula utilizada por el art. 7.2 LOPJ referente a una vinculación al contenido constitucionalmente declarado no significa en ningún caso que se pueda derivar una posible inaplicación de normas de carácter legislativo, ya que se sobreentiende que se debe aplicar el texto constitucional que afecte a derechos fundamentales de conformidad con la jurisprudencia constitucional de interpretación de los mismos y el desarrollo normativo adoptado por el legislador para restringir o configurar los derechos fundamentales. En caso contrario, se podría llegar a deducir que el poder judicial cuenta con un margen en la aplicación de los derechos fundamentales para limitarse exclusivamente a la aplicación del contenido constitucionalmente declarado deducible del precepto constitucional y de la jurisprudencia constitucional de delimitación e interpretación del mismo, pero no necesariamente una vinculación a las decisiones del legislador en la materia, lo que sería contrario al mandato constitucional de sometimiento genérico del poder judicial al imperio de la ley (art. 117.1 CE).

En definitiva, la actividad del poder judicial conectada a la vinculación positiva a los derechos fundamentales está sometida necesariamente al imperio de la ley (vinculación al principio de legalidad y juridicidad) ${ }^{52}$, pero evidentemente los órganos constitucionales pueden examinar la constitucionalidad de la ley, eventualmente plantear la cuestión de inconstitucionalidad, declarar la inaplicación o invalidez de los reglamentos y, finalmente, puede completar las lagunas jurídicas y complementar el derecho mediante la interpretación y la aplicación de la analogía, hecho que en materia de derechos fundamentales concede un rol fundamental al poder judicial mediante la aplicación directa de los derechos fundamentales, es decir, la posibilidad de resolver procesos o conflictos mediante la aplicación de preceptos constitucionales en ausencia o laguna de desarrollo normativo legislativo a los mismos ${ }^{53}$.

La aplicación de esta vinculación positiva del poder judicial se acentúa en el ámbito del proceso judicial con la finalidad de garantizar que, en el contenido de las sentencias, se adopten interpretaciones jurídicas conforme a la

52 Por todas, STC 39/1983 FJ 4

53 Sobre el problema de las lagunas en materia de derechos fundamentales, STERN, K., Das Staatsrecht der Bundesrepublik Deutschland. Bd. III/2, op. cit., pp. 1670 y ss. Un resumen de los criterios en materia de interpretación judicial en la doctrina alemana, SEILER, W., Höchstrichterliche Entscheidungsbegründungen und Methode im Zivilrecht, Nomos-Verl.-Ges., Baden-Baden, 1992. En la doctrina española, sobre la suplencia judicial del legislador en materia de derechos fundamentales, JIMÉNEZ CAMPO, J., Los derechos fundamentales. Concepto y garantias, Madrid, Trotta, 1999, pp. 59 y ss. Sobre la ponderación como tarea judicial y su relación con la ley, PRIETO SANCHIS, L., "El juicio de ponderación", en PRIETO SANCHIS, L., Justicia constitucional y derechos fundamentales, Trotta, Madrid, 2003, pp. 195 y ss. 
Constitución, lo que implica que cualquier medida judicial relacionada directa o indirectamente con los derechos fundamentales se debe motivar específicamente, determinado la importancia del derecho fundamental afectado en el caso concreto, con la finalidad de que la decisión pueda ser conocida por el afectado ${ }^{54}$. En este sentido, se debe destacar que las acciones positivas del poder judicial deben ser normalmente una consecuencia de una decisión legislativa en el ámbito del desarrollo normativo de un derecho fundamental, pero también es posible que la obligación sea un efecto de una interpretación asentada por el Tribunal Constitucional, sobre todo en relación con los derechos fundamentales de carácter procesal, es decir, vinculados al derecho a la tutela judicial efectiva o a las garantías del proceso debido (art. 24.1 y 2 CE), cuya interpretación permite sostener y extraer unos deberes positivos de protección y dotación de eficacia que alcanza específicamente a las funciones del poder judicial. Como consecuencia de este planteamiento se produce el efecto de vinculación positiva del poder judicial a las sentencias del Tribunal Constitucional (art. 5.1 LOPJ), cuyos precedentes pueden provocar la revisión de cualquier acto o decisión judicial ${ }^{55}$, pero también articular deberes positivos de protección y dotación de eficacia a los derechos fundamentales a la tutela judicial efectiva y a las garantías del proceso debido, cuyo principal destinatario es el propio poder judicial.

En estos supuestos, no se puede obviar que los órganos judiciales, cuando se estructura su deber de protección de los derechos fundamentales en el caso concreto tienen un margen de apreciación, ya que es difícil decidir normativa y regladamente una fórmula correcta de resolución de las específicas controversias con carácter general, por lo que en materia de derechos fundamentales se desplaza a la decisión del órgano judicial la valoración de las circunstancias en el caso concreto ${ }^{56}$. El Tribunal Constitucional en dicha valoración solo podrá revisar las decisiones judiciales que se basen en una incorrecta concepción y delimitación del ámbito constitucionalmente protegido del derecho fundamental ${ }^{57}$. Por otra parte, la dimensión objetiva de los derechos fundamentales implica que los órganos judiciales, al aplicar la norma penal, restrictiva de los derechos fundamentales por origen y contenido, tienen la obligación de tener presente el contenido constitucional de los derechos fundamentales a los que afecte, impidiendo reacciones que impliquen el sa-

54 STC 62/1982 FJ 2, que interrelación la falta de motivación con el derecho a la tutela judicial efectiva en el ejercicio de los derechos (art. 24.1 CE).

55 Por todas, STC 69/1992 FJ 4. Sobre la vinculación de la actividad judicial a los precedentes del Tribunal Constitucional, STERN, K., Das Staatsrecht der Bundesrepublik Deutschland. Bd. III/1, op. cit., pp. 1489 y ss. Sobre la vinculación del control judicial a los precedentes en materia de control de constitucionalidad de la ley, DÜWEL, M., Kontrollbefugnisse des Bundesverfassungsgerichts bei Verfassungsbeschwerden gegen gerichtliche Entscheidungen. Zu einem Kooperationsverhältnis von Fach - und Verfassungsgerichtsbarkeit, Nomos Verlagsgesellschaft, Baden-Baden, 2000, pp. 64 y ss.

56 ATC 382/1996 FJ 2

57 En el mismo sentido planteado por el ATC 382/1996 FJ 3, ATC 333/1997 FJ 3. 
crificio innecesario o desproporcionado de los mismos o que tengan un efecto disuasorio o desalentador de su ejercicio ${ }^{58}$. En consecuencia, no se pueden considerar como separados y compartimentos estancos el ámbito constitucional protegido en los derechos fundamentales y el ámbito punible ${ }^{59}$.

El recurso de amparo para el control de la actividad judicial en materia de derechos fundamentales se puede promover frente a las violaciones de derechos fundamentales y libertades públicas "que tuvieran su origen inmediato y directo en un acto u omisión de un órgano judicial" (art. 44 LOTC). Este recurso se dirige contra los órganos de la jurisdicción ordinaria, cuya principal función en la materia es precisamente proteger los derechos e intereses legítimos de todas las personas, de forma que una omisión o una protección insuficiente en cualquier proceso o actividad judicial que afecte a un derecho fundamental, convierte al poder judicial en infractor específico o derivado, es decir, directo o indirecto del derecho fundamental. Este hecho tiene un importante rol en materia de vinculación positiva de los órganos judiciales, ya que la ineficacia en la utilización de cualquier mecanismo de protección, o incluso la propia ineficacia en la protección, están comprendidas dentro de las actividades genéricas derivadas del art. $53.1 \mathrm{CE}$, implicando, en consecuencia, que el poder judicial sea el destinatario más importante de la vinculación positiva a los derechos fundamentales dentro del poder público. Las infracciones de derechos fundamentales pueden tener su origen, de conformidad con el art. 44 LOTC, tanto en actos como en omisiones realizadas por órganos judiciales $^{60}$. Entre los actos judiciales se incluyen las sentencias y todas las actuaciones judiciales susceptibles de lesionar alguno de los derechos fundamentales (providencias, autos, mandamientos o cualquier otra resolución judicial). Desde la perspectiva de la vinculación positiva, cualquier acto judicial es controlable en la medida que puede suponer un incumplimiento incorrecto de la obligación positiva encomendada al órgano judicial en conexión con la protección eficacia de un derecho fundamental.

La vinculación positiva del poder judicial a los derechos fundamentales se puede interrelacionar a partir de dos esquemas de funcionamiento, de forma indirecta afecta a todos los derechos fundamentales en los que actúa de forma no específica y de forma directa afecta a los derechos que se interrelaciona de forma específica con la función judicial. Cuando el poder judicial actúa como destinatario indirecto de los derechos fundamentales, al no ejercer funciones específicas en relación con los mismos, no es sujeto pasivo principal de dichos derechos fundamentales, pero debe cumplir su función genérica de

58 STC 85/1992 FJ 4, STC 136/1999 FJ 20, STC 110/2000 FJ 5, STC 2/2001 FJ 3, STC 196/2002 FJ 6.

59 ATC 377/2004 FJ 1.

60 Sobre el alcance y el significado de las acciones y omisiones judiciales como objeto del amparo, vid. GARCÍA MURCIA, J., "Comentarios al art. 44 LOTC", en REQUEJO PAGÉS, J. L. (Coord.), Comentarios a la Ley Orgánica del Tribunal Constitucional, Tribunal Constitucional-BOE, Madrid, 2001, pp. 705-706. 
protector y garante de los derechos fundamentales, aplicándose en general a cualquier derecho fundamental, salvo en los que actúa como destinatario principal o específico ${ }^{61}$.

Dentro del ámbito de la vinculación positiva de los órganos judiciales conectados a su papel de destinatario indirecto, se pueden destacar dos sectores importantes en los que se despliega el alcance del control de la protección desempeñada por los órganos judiciales a los derechos fundamentales. En este sentido, por una parte, se comprueba si se han cumplido las obligaciones constitucionales en materia de motivación de las resoluciones judiciales como criterio trasversal aplicable a cualquier proceso, pero especialmente determinante cuando el poder judicial desempeña su rol de garante de los derechos fundamentales y, por otra parte, la comprobación del cumplimiento de la función judicial en materia de ponderación judicial de derechos fundamentales, es decir, cuando en virtud de un mandato constitucional se requiere específica y exclusivamente que los órganos judiciales determinen mediante una decisión el alcance y el ejercicio correcto de un derecho fundamental en un caso concreto, con la finalidad de la resolución de un conflicto entre derechos o para el control de la constitucionalidad y de la legalidad de una intervención en un derecho ${ }^{62}$.

En el segundo esquema de funcionamiento, la vinculación positiva cuando se interrelaciona con el papel del poder judicial como destinatario directo de los derechos fundamentales, responde más a los criterios ya analizados en relación con otros supuestos, es decir, se requiere una ley que establezca las acciones positivas de protección y dotación de eficacia de los derechos fundamentales, pero relacionada estructuralmente a unos derechos concretos en los que el poder judicial ejerce unas funciones específicas y estrictas determinadas directamente por la Constitución, afectando básicamente a los derechos fundamentales de carácter procesal como la tutela judicial efectiva y las garantías del proceso debido (art. $24 \mathrm{CE})^{63}$.

La vinculación positiva de los órganos judiciales cuando actúan como destinatario indirecto de los derechos fundamentales, implica la aplicación de un criterio trasversal como es la determinación del alcance de la exigencia constitucional de la motivación de cualquier resolución judicial que implique de acciones positivas de protección o dotación de eficacia a los derechos fundamentales, pero además cuando la vinculación positiva se conecta a la respuesta resolutiva de una restricción de un derecho fundamental como con-

61 Sobre la vinculación del poder judicial a los derechos fundamentales con carácter material, vid. STERN, K., Das Staatsrecht der Bundesrepublik Deutschland. Bd. III/1, op. cit., pp. 1472 y ss.

62 Sobre la corrección del significado de los derechos fundamentales en las decisiones judiciales, DÜWEL, M., Kontrollbefugnisse des Bundesverfassungsgerichts bei Verfassungsbeschwerden gegen gerichtliche Entscheidungen, op. cit., pp. 48 y ss.

63 Con carácter general, en la doctrina alemana, sobre el contenido de una protección jurídica efectiva y su alcance, STERN, K., Das Staatsrecht der Bundesrepublik Deutschland. Bd. III/1, op. cit., pp. 1442-1443. 
secuencia de una habilitación legislativa para el desarrollo del derecho fundamental, la exigencia constitucional de motivación de las resoluciones judiciales opera de una forma más estricta ${ }^{64}$.

En materia de motivación de las decisiones judiciales relacionadas con los derechos fundamentales, la cuestión no afecta tanto a la determinación formal del sujeto que deviene obligado a motivar sus decisiones, sino que el control cuando la decisión afecte a los derechos fundamentales es operativo sobre el modo de fundamentar materialmente las decisiones. En consecuencia, no solo es importante la existencia formal de motivación, sino el contenido material de la misma y la aplicación de unos principios de carácter genérico que se podrán ir deduciendo de la jurisprudencia del Tribunal Constitucional sobre el alcance de dicha motivación ${ }^{65}$, teniendo en consecuencia una importante función para facilitar el control externo en materia de derechos fundamentales, siendo un instrumento relevante para la protección efectiva de los derechos fundamentales a partir del control del contenido material de las resoluciones judiciales en la materia ${ }^{66}$. La motivación de las decisiones judiciales en materia de derechos fundamentales tiene carácter específico, que casi la asemeja a la motivación del acto administrativo, por la necesidad de respetar el aspecto formal y material, provocado sobre todo por la dimensión procesal de los derechos y la necesidad de articular controles judiciales de garantía en materia de derechos fundamentales ${ }^{67}$.

64 Por todas, STC 62/1982 FJ 2. Sobre la obligación de motivación de las decisiones judiciales en la doctrina alemana, LÜCKE, J., Begründungszwang und Verfassung. Zur Begründungspflicht der Gerichte, Behörden und Parlamente, Mohr Siebeck, Tübingen, 1987, pp. 1 y ss.; BRINK, S., Über die richterliche Entscheidungsbegründung. Funktion - Position - Methodik, Lang, Frankfurt am Main [u.a.], 1999, pp. 46 y ss.; KISCHEL, U., Die Begründung, op. cit., pp. 176 y ss. En la doctrina italiana, TARUFFO, M., La motivazione della sentenza civile, Cedam, Padova, 1975, pp. 392 y ss.; CARETTI, P., "Motivazione I. Diritto Costituzionale", Enciclopedia Giuridica Treccani, Roma, 1989, pp. 2 y ss. En la doctrina española, sobre la construcción de la motivación judicial como categoría jurídica, así como un análisis de sus principales contenidos, en NIETO, A., El arbitrio judicial, Ariel, Barcelona, 2000, pp. 139 y ss. Desde un punto de vista teórico sobre la infracción de la motivación a partir de su ausencia, insuficiencia o contradicción interna, IGARTUA SALAVERRÍA, J., La motivación de las sentencias, imperativo constitucional, CEPC, Madrid, 2003, pp. 202 y ss. También en la doctrina italiana, la motivación de las decisiones se construye como una obligación específica del juez, DELLA MONICA, G., Contributo allo studio della motivazione, CEDAM, Padova, 2002, 8 y ss.

65 Sobre los principios de carácter material que deben regir en materia de motivación, KISCHEL, U., Die Begründung, op. cit., pp. 335 y ss.

66 LÜCKE, J., Begründungszwang und Verfassung, op. cit., pp. 46 y ss.

67 Sobre la motivaciones de las decisiones judiciales en materia de derechos fundamentales, ANGIOLINI, V., "Giurisdizione (reserva di)", AAVV, Digesto delle discipline pubblicistiche, UTET, Torino, 1992, pp. 350 y ss.; ANGIOLINI, V., Riserva di giurisdizione e libertà costituzionali, Cedam, Padova, 1992, 31 y ss.; BIN, R., Diritti e argomenti. Il bilanciamento degli interessi nella giurisprudenza costituzionale, Giuffrè, Milano, 1992, pp. 140 y ss. En la doctrina española, con abundante información bibliográfica, RODRÍGUEZ BOENTE, S. E., La justificación de las decisiones judiciales. El artículo 120.3 de la Constitución Española, Universidade de Santiago de Compostela, Santiago de Compostela, 2003, pp. 254 y ss. Sobre el carácter específico de las decisiones judiciales de restricción de los derechos fundamentales, COLOMER HERNÁNDEZ, I., La motivación de las sentencias. Sus exigencias constitucionales y legales, Tirant lo Blanch, València, 2003, pp. 
En este sentido, ya se empieza a apuntar la necesidad de que las motivaciones de las decisiones judiciales en materia de derechos fundamentales aporten algún contenido de carácter diferenciado sobre la obligación de motivación de carácter genérico, y ello con independencia de que está obligación de motivación de las decisiones judiciales con carácter genérico se pueda integrar dentro de las garantías constitucionales conectadas a los derechos de los justiciables ${ }^{68}$, lo que no deja de ser una consecuencia de que la motivación es un elemento de control de control de la aplicación de las garantías constitucionales por parte del poder judicial en especial ${ }^{69}$. Esta diferenciación entre las motivaciones de las decisiones judiciales se puede estructurar en torno a la distinción entre justificación interna y externa, de forma que la motivación de las decisiones judiciales en materia de derechos fundamentales exigiría tanto una justificación interna como externa, mientras que la motivación de carácter genérico tan solo plantearía la necesidad de una justificación interna ${ }^{70}$.

La justificación interna tiene carácter formal centrada en la fijación de unas condiciones de corrección conectadas a su consistencia interna, la vinculación y el respeto de la legalidad y constitucionalidad relacionada con una coherencia interna, la fundamentación material relacionada con la coherencia externa y, por último, la plenitud que implica la deducción de las consecuencias a partir de las premisas sin selección subjetiva ni ignorancia de las mismas, es decir, se controla la validez de la inferencia de las conclusiones a partir de las premisas.

161 y ss. Sobre la interrelación entre la dimensión procesal de los derechos fundamentales y la obligación de motivación de las decisiones judiciales, KISCHEL, U., Die Begründung, op. cit., pp. 123 y ss.; en particular, pp. 128-130, en el que se especifica la utilización de la motivación como mecanismo o función de protección de los derechos fundamentales.

68 Como veremos la obligación de motivación se integra en el art. 24.1 CE. Por todos, COLOMER HERNÁNDEZ, I., La motivación de las sentencias, op. cit., pp. 90 y ss.

69 DELLA MONICA, G., Contributo allo studio della motivazione, op. cit., pp. 3 y ss.

70 Sobre la distinción entre justificación interna y externa de las decisiones judiciales es básico, WROBLEWSKI. J., "Motivation de la decisión judiciaire", en AAVV, La motivation des décisions de Justice, E. Bruylant, Bruxelles, 1978, pp. 119-120; WROBLEWSKI. J., "Legal Decisión and its Justification", en AAVV, Le raisonnement juridique. Actes du Congrès mondial de philosophie du droit et de philosophie sociale, E. Bruylant, Bruxelles, 1971, pp. 405 y ss.; WROBLEWSKI. J., Constitución y teoría general de la interpretación jurídica, Civitas, Madrid, 1985, pp. 57 y ss. En la doctrina alemana, vid., ALEXY, R., Teoría de la argumentación jurídica. La teoría del discurso racional como teoría de la fundamentación jurídica, CEC, Madrid, 1989, pp. 273 y ss.; BUCHWALD, D., "Die Canones der Auslegung und rationale juristische Begründung", ARSP, 1993, vol. 79, Heft 1, pp. 16 y ss., que hace hincapié en los canones de fundamentación racional de la interpretación de las normas, pp. 29 y ss.; CHANG, Ch.-Y., Zur Begründung und Problematik der objektiven Dimension der Grundrechte, Lang, Frankfurt am Main [u.a.], 2000, pp. 87 y ss. En la doctrina española, RODRÍGUEZ BOENTE, S. E., La Justificación de las decisiones judiciales, op. cit., pp. 122 y ss.; ITURRALDE SESMA, V., Aplicación del derecho y justificación de la decisión judicial, Tirant lo Blanch, Valencia, 2003, pp. 279 y ss., pp. 369 y ss. a partir de la consideración de la justificación externa como criterio de validez material de justificación y la justificación interna como criterio de validez formal. En la doctrina italiana, TARUFFO, M., La motivazione della sentenza civile, op. cit., pp. 277 y ss. (que distingue entre justificación interna como inferencia de las conclusiones a partir de las premisas y justificación externa a partir de las argumentaciones realizadas) y conectado a la motivación como justificación racional de la decisión, BIN, R., Diritti e argomenti, op. cit., pp. 142 y ss. 
La justificación externa tiene un carácter material, que exige respeto de la legitimidad y de las normas de competencia para la adopción de las decisiones, una corrección, información y especificidad a partir de la conexión de las conclusiones con el caso concreto basada no solo en la existencia de la fundamentación, sino también en su deducción de las premisas, la ponderación del derecho fundamental afectado en el caso y una coherencia de carácter sistemático a partir del respeto de la unidad del ordenamiento, sin uso arbitrario o con error patente de las fuentes del Derecho aplicables en concreto, es decir, una justificación sustancial y exteriorizada a partir del examen de las argumentaciones utilizadas por el órgano judicial.

Este esquema de ponderación judicial se aplica a límites expresos que supongan o permitan una resolución de conflictos entre derechos a nivel constitucional (conflicto entre el derecho a la libertad de expresión y de información — art. 20.1 CE - con los derechos al honor, a la intimidad y a la propia imagen - art. 20.4 CE-), a supuestos de reserva jurisdiccional en la intervención concreta de derechos (art. 18.2 y 3 CE) o a supuestos de exigencia legal, no expresamente establecida en la Constitución, como consecuencia de la resolución legal de un conflicto entre derechos de una autorización judicial expresa para la realización de intervenciones en derechos fundamentales concretos (intervenciones e inspecciones corporales) ${ }^{71}$.

En estos tres supuestos, resolución del conflicto entre derechos expresamente establecido en la Constitución, intervención de un derecho sometido a reserva de jurisdicción por la Constitución y resolución de un conflicto mediante decisión del legislador, las actividades judiciales integradas en la vinculación positiva implica la adopción de decisiones y resoluciones en las que debe desplegar una motivación o ponderación debiendo valorar específicamente los derechos desplegados con la finalidad de dotar de la eficacia necesaria y justa a cada uno de los derechos en función de las circunstancias concretas del $\mathrm{CasO}^{72}$.

71 Una parte de la doctrina considera que la intervención judicial en materia de derechos fundamentales es una función de carácter no jurisdiccional, SÁNCHEZ BARRILAO, J. F., Las funciones no jurisdiccionales de los jueces en garantía de derechos, Civitas, Madrid, 2002, pp. 153 y ss. Esta postura implica que los mecanismos de protección de los derechos fundamentales que necesitan autorización judicial son consideradas actuaciones preventivas, reservando en consecuencia el carácter jurisdiccional para las actuaciones de carácter represivo. La resolución judicial adoptada en el caso concreto se basa en un expediente sin contradicción, aunque la actividad judicial no se acaba en la adopción de la decisión de intervención de los derechos fundamentales, sino que se ejerce también el control sobre la efectiva ejecución de la medida adoptada. El argumento de base del autor considera que el monopolio de jurisdicción alcanza tan solo a las previsiones del art, 117.3 CE (juzgar y hacer ejecutar lo juzgado), mientras que todas las previsiones del art. 117.4 CE se caracterizarían como actividades no jurisdiccionales (pp. 168-169).

72 Sobre la ponderación judicial y su significado en materia de derechos fundamentales, PRIETO SANCHIS, L., "El juicio de ponderación", en PRIETO SANCHIS, L., Justicia constitucional $y$ derechos fundamentales, op. cit., pp. 189 y ss.; JIMÉNEZ CAMPO, J., Los derechos fundamentales, op. cit., pp. 55 y ss.; DÍEZ-PICAZO, L. M., Sistema de derechos fundamentales, Madrid, Civitas, 2003, pp. 46 y ss. 
La ponderación judicial ha sido objeto tradicional de críticas y objeciones, debido fundamentalmente a que implica un grado de apertura a la decisión jurisdiccional en materia de derechos fundamentales ${ }^{73}$. No obstante, lo cierto es que la existencia de un control posterior por parte del Tribunal Constitucional, una jurisprudencia consolidada sobre los criterios de carácter material que se debe observar y aplicar, convierte a la ponderación en una actividad reglada basada fundamentalmente en una vinculación a los precedentes anteriores $^{74}$. En todo caso, el control posterior se convierte en un elemento necesario para la admisión de la ponderación judicial en materia de derechos fundamentales, ya que al ser un efecto exigido y permitido por la Constitución, el problema no radica en su existencia, sino en el modo de utilización de la competencia. En la medida que la ponderación suponga una intervención intensa en el derecho fundamental, el control debe ser operativo sobre la justificación interna o formal, es decir, el procedimiento de inferencia de la sentencia y sobre la justificación externa o material que afecta a los argumentos utilizados, a partir de la intensidad del perjuicio que se produce en el derecho fundamental ${ }^{75}$. En el resto de los casos se produce un control basado en la obligación de motivación de las decisiones judiciales con carácter general.

\section{LA INCIDENCIA Y LAS CONSECUENCIAS ESTRUCTURALES Y FUNCIONALES DE LA VINCULACIÓN POSITIVA DE CARÁCTER OBJETIVO EN LOS DERECHOS FUNDAMENTALES}

La vinculación positiva de carácter objetivo implica el análisis y descripción del conjunto de acciones positivas de protección o dotación de contenido y eficacia a los derechos fundamentales desarrolladas y adoptadas por el poder público en el que se plasma el deber de protección genérico de los derechos fundamentales por parte de los poderes públicos establecido en el art. 53.1 CE, con la finalidad de estructurar y determinar las consecuencias para

73 Sobre casos de incorrecta protección de los derechos fundamentales en la doctrina alemana, DÜWEL, M., Kontrollbefugnisse des Bundesverfassungsgerichts bei Verfassungsbeschwerden gegen gerichtliche Entscheidungen, op. cit., pp. 83 y ss. Un resumen de las objeciones al método ponderativo en UGARTEMENDIA ECEIZABARRENA, J. I., La eficacia justificante de los derechos. Análisis de la eximente de ejercicio legítimo de un derecho $\left(20.7 .{ }^{\circ} \mathrm{CP}\right)$ desde una perspectiva constitucional, Tirant lo Blanch, Valencia, 2003, pp. 215 y ss. Un resumen de los supuestos de ponderación judicial entre derechos en la doctrina alemana, SCHNEIDER, H., Die Güterabwägung des Bundesverfassungsgerichts bei Grundrechtskonflikten, op. cit., pp. 43 y ss.

74 Sobre el control de la ponderación judicial en la doctrina alemana, MIEBACH, M., Zur Willkür - und Abwägungskontrolle des Bundesverfassungsgerichts bei der Verfassungsbeschwerde gegen Gerichtsurteile, Florentz, München, 1990, pp. 108 y ss.

75 Sobre la conveniencia de introducir criterios sobre la intensidad del perjuicio en el derecho fundamental a efectos del control de las decisiones judiciales, DÜWEL, M., Kontrollbefugnisse des Bundesverfassungsgerichts bei Verfassungsbeschwerden gegen gerichtliche Entscheidungen, op. cit., pp. 92 y ss. 
los sujetos públicos y privados, titulares y destinatarios de los derechos fundamentales, afectados por dichas acciones positivas de protección y dotación de contenido y eficacia desarrolladas y adoptadas por el poder público. Una vez examinados los mecanismos subjetivos de articulación de los medios de protección y eficacia se deben determinar los efectos que producen materialmente en los derechos fundamentales a partir de la diferenciación entre derechos de defensa y derechos de prestación, como reflejos directos y distintos de la vinculación negativa y positiva respectivamente.

La efectiva protección y dotación de eficacia de los derechos fundamentales, desde un punto de vista fáctico, depende de los medios materiales y personales del poder público, principalmente de carácter jurisdiccional, y de la capacidad de prestación que posea el Estado. Los principales factores que inciden en la efectiva protección de los derechos fundamentales, como serían la resolución de las pretensiones y los conflictos de los ciudadanos en la materia, la defensa y protección jurídica de los derechos fundamentales, así como su configuración a través de la ley y su garantía a través del procedimiento y del proceso judicial, el control de la actividad de los órganos del poder relacionados con los derechos y con las actuaciones de los ciudadanos como destinatarios de los derechos fundamentales y, de forma evidente, también las funciones de prestación vinculadas a los contenidos positivos de los derechos fundamentales, dependen en su práctica totalidad de la actividad de desarrollo de los derechos fundamentales por parte de los poderes públicos que desempeñan sus funciones de acuerdo con su competencia jurídica, territorial, administrativa y política ${ }^{76}$.

Esta dependencia del poder público permite deducir que la protección del ejercicio de los derechos fundamentales se puede determinar a partir de factores externos al propio contenido de los derechos fundamentales, que son susceptibles de ser configurados y determinados jurídicamente por el poder constituido, que permite concluir que el ejercicio, la protección y la eficacia de los derechos fundamentales se determinan de forma plena y definitiva mediante decisiones jurídicas infraconstitucionales ${ }^{77}$.

La vinculación positiva implica el desarrollo práctico de una obligación de carácter constitucional para la protección por parte de los poderes públicos, como mecanismo de la seguridad que se debe prestar a los ciudadanos ${ }^{78}$. La vincula-

76 Sobre la dependencia de la eficacia de los derechos fundamentales de la acción de los poderes públicos, ISENSEE, J., "Grundrechtsvoraussetzungen und Verfassungserwartungen an die Grundrechtsausübung", en ISENSEE, J.-KIRCHHOF, P. (hrsg.), Handbuch des Staatsrechts der Bundesrepublik Deutschland, Bd. V, C.F. Müller Verlag, Heidelberg, 1992, pp. 408 y ss.; LADEUR, K.-H., Kritik der Abwägung in der Grundrechtsdogmatik. Plädoyer für eine Erneuerung der liberalen Grundrechtstheorie, Mohr Siebeck, Tübingen, 2004, pp. 36 y ss.

77 Vid. BRACZYK, B. A., Rechtsgrund und Grundrecht. Grundlegung einer systematischen Grundrechtstheorie, Duncker und Humblot, Berlin, 1996, pp. 74 y ss.

78 Sobre la fundamentación dogmática e histórica de la obligación de protección, con carácter general, MURSWIEK, D., Die Staatliche Verantwortung für die Risiken der Technik. Verfassungsrechtliche Grundlagen und immissionsschutzrechtliche Ausformung, Duncker \& Humblot, Berlin, 1985; HERMES, G., Das Grundrecht auf Schutz von Leben und Gesundheit. Schutzp- 
ción positiva se produce con independencia de que sea necesario que el poder público, especialmente el legislador, deba determinar las circunstancias de protección y el alcance de la protección de los derechos fundamentales, tanto en abstracto como en el caso concreto, ya que no aparecen determinadas en la Constitución ${ }^{79}$. En este sentido, la vinculación positiva a los derechos fundamentales ha dado lugar a una categoría dogmática autónoma conocida en la doctrina alemana como la obligación de protección estatal de los derechos fundamentales ${ }^{80}$, que se justifica frente a las infracciones o amenazas de perjuicio que pueda ocasionar un tercero ${ }^{81}$, pero susceptible de extenderse a cualquier situación en la que se necesite proteger o dotar de eficacia un derecho fundamental.

La vinculación positiva requiere una estructura de desarrollo que establezca y reconozca los presupuestos para que se pueda articular por parte del legislador, así como las circunstancias de su aplicación en los casos concretos, aunque se debe tener en cuenta que se trata de unos criterios que funcionan como pautas dogmáticas, sin valor normativo, de forma que se puede considerar que la estructura de la obligación de protección estatal de los derechos fundaméntales puede ser heterogénea ${ }^{82}$. De todos modos, a efectos descriptivos la estructura dogmática del establecimiento en normas jurídicas de la vinculación positiva de carácter objetivo articulada en torno a las obligaciones de protección y dotación de eficacia supone el análisis de las siguientes cuestiones ${ }^{83}$ :

flicht und Schutzanspruch aus Art. 2 Abs. 2 Satz 1 GG, Müller, Jurist. Verl., Heidelberg, 1987; DIETLEIN, J., Die Lehre von den grundrechtlichen Schutzpflichten, op. cit., pp. 21 y ss.; UNRUH, P., Zur Dogmatik der grundrechtlichen Schutzpflichten, op. cit., pp. 37 y ss.; KRINGS, G., Grund und Grenzen grundrechtlicher Schutzansprüche, op. cit., pp. 28 y ss. Sobre la conexión de la vinculación positiva con el deber del poder público de dotar de seguridad a la sociedad, ISENSEE, J., Das Grundrecht auf Sicherheit. Zu den Schutzpflichten des freibeitlichen Verfassungsstaates, Walter de Gruyter, Berlin, 1983; MÖSTL, M., Die staatliche Garantie für die öffentliche Sicherheit und Ordnung. Sicherheitsgewährleistung im Verfassungsstaat, im Bundesstaat und in der Europäischen Union, Mohr Siebeck, Tübingen, 2002.

79 Sobre la diferencia entre la existencia y el modo de protección de los derechos fundamentales, CANARIS, Cl.-W., Grundrechte und Privatrecht, op. cit., pp. 71 y ss.

80 Sobre la defensa de la obligación de protección estatal como categoría autónoma, DOLDERER, M., Objektive Grundrechtsgehalte, op. cit., pp. 177 y ss.; MAYER, M., Untermaß, Übermaß und Wesensgehaltgarantie, op. cit., pp. 55 y ss. Sobre el reconocimiento de la obligación de protección estatal por el Tribunal Constitucional alemán, ISENSEE, J., Das Grundrecht auf Sicherheit, op. cit., pp. 27 y ss.; MAYER, M., Untermaß, Übermaß und Wesensgehaltgarantie, op. cit., pp. 20 y ss.; DOLDERER, M., Objektive Grundrechtsgehalte, op. cit., pp. 177 y ss.; KRINGS, G., Grund und Grenzen grundrechtlicher Schutzansprüche, op. cit., pp. 60 y ss. Un resumen debla problemática en LINKE, T., Grundrechtliche Spannungslagen am Lebensende. Zur Bedeutung der grundrechtlichen Abwehrrechte, Schutzpflichten und Leistungsaspekte für die Sterbehilfe, Nomos Verlagsgesellschaft, Baden-Baden, 2004, pp. 40 y ss.; CREMER, W., Freiheitsgrundrechte, op. cit., pp. 228 y ss. En la doctrina austriaca, HOLOUBEK, M., Grundrechtliche Gewährleistungspflichten, op. cit., pp. 243 y ss. En la doctrina española, con indicaciones jurisprudenciales, DOMÉNECH PASCUAL, G., Derechos fundamentales y riesgos tecnológicos, op. cit., pp. 81 y ss.; pp. 123 y ss.

81 LINDNER, J. F., Theorie der Grundrechtsdogmatik, Tübingen, Mohr Siebeck, 2005, p. 369 82 LINDNER, J. F., Theorie der Grundrechtsdogmatik, op. cit., pp. 362 y ss.

83 Sobre la estructura de la obligación de protección de los derechos fundamentales, CREMER, W., Freiheitsgrundrechte, op. cit., pp. 264 y ss.; JAECKEL, L., Schutzpflichten im deutschen 
A) El supuesto de hecho que desencadena la acción positiva de los poderes públicos para la protección de los derechos fundamentales es la situación de peligro para el derecho fundamental, es decir, una injerencia o abuso por parte de terceros que puedan perjudicar su contenido ${ }^{84}$. Además, dejando al lado el peligro de injerencia por parte de personas privadas, se articula normativamente el contenido positivo del alcance de los derechos de prestación o las obligaciones de protección expresa de los derechos de defensa para evitar posibles omisiones de los poderes públicos en fase de aplicación del derecho que incidirían y repercutirían en la protección y dotación de eficacia a los derechos fundamentales. En relación a este supuesto de hecho se debe destacar, cuando se está analizando por parte de los poderes públicos una intervención o peligro de injerencia de personas privadas frente a derechos fundamentales ajenos, que el objeto de dicha intervención o peligro en el caso de los derechos fundamentales siempre es el ámbito de protección del derecho fundamental que se integra por el bien jurídico protegido (vida, propiedad, libertad personal), el supuesto de hecho y el alcance normativo a partir del objeto material de protección, es decir, la realidad fáctica y material afectada por el derecho fundamental. De este modo, la incidencia en cualquiera de estos elementos por una intervención o peligro de injerencia por parte de un tercero puede desarrollar y derivar la utilización de instrumentos de vinculación positiva a los derechos fundamentales. Las formas de perjuicio o de puesta en peligro de dicho contenido material de los derechos fundamentales puede ser de carácter fáctico o jurídico y de muy diversa naturaleza como la coacción, ausencia de reconocimiento de libertad o de protección, censura, obligación o prohibición en el ámbito del derecho, registro o expropiación ${ }^{85}$, de modo que se puede considerar que tanto implica una infracción de los derechos fundamentales una acción jurídica, como fáctica

und europäischen Recht. Eine Untersuchung der deutschen Grundrechte, der Menschenrechte und Grundfreiheiten der EMRK sowie der Grundrechte und Grundfreiheiten der Europäischen Gemeinschaft, Nomos-Verl.-Ges., Baden-Baden, 2001, pp. 62 y ss.; ISENSEE, J., "Das Grundrecht als Abwehrrecht und als Schutzpflicht", en ISENSEE, J.-KIRCHHOF, P. (Hrsg.), Handbuch des Staatsrechts der Bundesrepublik Deutschland, Bd. V, op. cit., pp. 188 y ss.; UNRUH, P., Zur Dogmatik der grundrechtlichen Schutzpflichten, op. cit., pp. 74 y ss.; HORN, H.-D., Die grundrechtsunmittelbare Verwaltung, op. cit., pp. 184 y ss.

84 Sobre la conexión de la obligación de protección estatal frente a los perjuicios que puedan ocasionar terceras personas, incluso en el ejercicio de sus propios derechos, SCHWABE, J., Probleme der Grundrechtsdogmatik, Darmstadt, 1977, pp. 211 y ss.; MISERA-LANG, K., Dogmatische Grundlagen der Einschränkbarkeit vorbehaltloser Freiheitsgrundrechte, Lang, Frankfurt am Main [u.a.], 1999, pp. 238 y ss.; KOCH, TH., Der Grundrechtsschutz des Drittbetroffenen. Zur Rekonstruktion der Grundrechte als Abwehrrechte, Mohr Siebeck, Tübingen, 2000, pp. 211 y ss., que es el estudio más completo en la doctrina alemana sobre la materia. En la doctrina italiana, vid. MORELLI, G., La sospensione dei diritti fondamentali nello stato moderno. La legge fondamentale di Bonn comparata con le Costituzioni francese e italiana, Giuffrè, Milano, 1966, pp. 176 y ss.

85 Sobre las formas de perjuicio fáctico o jurídico, vid. GALLWAS, H.-U., Faktische Beeinträchtigungen im Bereich der Grundrechte, op. cit., pp. 149 y ss.; ROTH, W., Faktische Eingriffe in Freibeit und Eigentum. Struktur und Dogmatik des Grundrechtstatbestandes und der Eingriffsrechtfertigung, Duncker und Humblot, Berlin, 1994, pp. 166 y ss., pp. 230 y ss.; KOCH, TH., Der Grundrechtsschutz des Drittbetroffenen, op. cit., pp. 213 y ss. 
o las omisiones a los comportamientos debidos o prescritos normativamente ${ }^{86}$ Por otra parte, en el caso de los derechos de prestación el objeto será la configuración jurídica de la obligación estatal de carácter fáctico o de adopción de decisiones públicas en materia de prestación que puede afectar a cualquier elemento no articulado del derecho fundamental que contribuye a determinar la vinculación positiva del poder público para la protección y dotación de eficacia a los derechos fundamentales. En cualquier caso, los propios derechos fundamentales se constituyen en la base o fundamento de un derecho constitucional subjetivo a la protección estatal del $\mathrm{mismo}^{87}$, con independencia de que se considere que constituye una categoría jurídica o que tiene carácter autónomo dicho derecho a la protección.

B) La consecuencia jurídica que implica la estructuración normativa de la vinculación positiva de carácter objetivo a los derechos fundamentales es la actualización de la función estatal de protección y dotación de eficacia de los mismos, tanto desde el aspecto de defensa como de articulación normativa de acciones positivas y prestaciones, sobre todo en los procesos de aplicación del derecho y la selección del medio para realizar efectivamente la protección del derecho por parte de los poderes públicos, generalmente como respuesta frente a posibles injerencias y abusos de personas privadas en derechos fundamentales ajenos, o a la insuficiencia de los mecanismos establecidos directamente por la Constitución.

El medio utilizado para la protección del derecho fundamental y articulado legislativamente se debe fundamentar en criterios constitucionales de conformidad con el orden y normas de competencia, la reserva de ley y la protección de los derechos de terceras personas, es decir, es admisible un examen sobre la base de su justificación en la Constitución, tal como tuvimos ocasión de examinar en relación con la vinculación positiva de carácter subjetivo. Estos medios pueden tener una naturaleza represiva frente a infracciones o una naturaleza preventiva frente a peligros de injerencias en los derechos fundamentales por parte de terceros ${ }^{88}$. En cualquier caso, antes de decidir adoptar medidas de carácter preventivo o represivo existen diversos criterios que se deben valorar en la protección de los derechos fundamentales como la imposibilidad material, técnica o jurídica de desplegar o decidir los medios de protección, la responsabilidad primaria del individuo o titular de desplegar la protección del derecho fundamentales mediante los medios generales u ordinarios antes de decidir los medios concretas o específicos, la valoración de la situación de riesgo concreta

86 Vid. ARANGO, R., El concepto de derechos sociales fundamentales, op. cit., pp. 183 y ss. 87 DIETLEIN, J., Die Lehre von den grundrechtlichen Schutzpflichten, op. cit., pp. 152 y ss.

88 En la doctrina española sobre medios de reparación o de medidas de protección de los derechos fundamentales, DÍEZ-PICAZO, L. M., Sistema de derechos fundamentales, op. cit., pp. 91 y ss.; DOMÉNECH PASCUAL, G., Derechos fundamentales y riesgos tecnológicos, op. cit., pp. 146 y ss. Sobre los medios de protección de los derechos fundamentales, ISENSEE, J., Das Grundrecht auf Sicherheit, op. cit., pp. 38-39. En general, sobre la protección jurídica de los derechos fundamentales como garantía constitucional y sus medios, LORENZ, D., "Der grundrechtliche Anspruch auf effektiven Rechtsschutz", AöR, 1980, Bd. 105, Heft 4, pp. 625 y ss. 
del derecho fundamental, la existencia de posturas contrapuestas y la determinación sobre si el perturbador está ejerciendo un derecho fundamental con carácter legítimo y, finalmente, la posible necesidad de determinar medidas de solución de conflictos por parte de los poderes públicos ${ }^{89}$. Las medidas represivas a adoptar frente a los perjuicios realizados por personas privadas tienen carácter imperativo a través de la imposición de obligaciones concretas o prohibiciones legales, precisando de autorizaciones administrativas para la realización de determinadas actividades ${ }^{90}$. La concreción de estas medidas depende del grado de tolerancia estatal admisible sobre los comportamientos y sobre la admisión por parte del control externo del grado de injerencia estatal para el cese del perjuicio o de la producción del daño en el derecho fundamental ${ }^{91}$. En general, su ejecución dependerá de la actividad administrativa o eventualmente del poder judicial. Las medidas represivas pueden articularse a través de procedimientos de solicitud de responsabilidad penal o civil. Las medidas preventivas tratan de evitar que terceras personas puedan infringir o poner el peligro el ejercicio de un derecho fundamental, pudiendo estar vinculadas a la solicitud o búsqueda de información, a procedimientos de inspección y vigilancia, a la comprobación de datos o realización de investigaciones administrativas, con la finalidad de evitar una posible infracción en el derecho fundamental ${ }^{92}$.

C) Los presupuestos para la aplicación de la vinculación positiva a los derechos fundamentales, es decir, el medio positivo de protección y dotación de eficacia elegido por el legislador, en especial las medidas contra el perturbador o perjudicador y el análisis de su estatuto básico en tanto que infractor de un derecho fundamental. Las consecuencias de la falta de respeto a los derechos fundamentales de las terceras personas se deben fijar mediante ley, pudiendo implicar eventualmente sanciones penales o administrativas o, desde un punto de vista de la fijación de conductas, el establecimiento de comportamientos obligatorios de las que se derivan posteriores consecuencias jurídicas.

D) La situación jurídica del titular del derecho fundamental frente a la infracción o peligro de injerencia en el mismo, que implica eventualmente el análisis del derecho subjetivo de protección, las posibilidades de apertura de acciones procesales, la exigencia de comportamientos a personas privadas o cumplimiento de obligaciones por parte de los poderes públicos, desde la perspectiva de la mera legalidad, o incluso completar y desarrollar normas

89 MAYER, M., Untermaß, Übermaß und Wesensgehaltgarantie, op. cit., pp. 57 y ss.

90 Para una descripción de las fuentes de peligro en los derechos fundamentales a través de perjuicios en los derechos fundamentales, JAECKEL, L., Schutzpflichten im deutschen und europäischen Recht, op. cit., pp. 63 y ss., pp. 66 y ss.

91 Sobre la obligación de tolerancia del ejercicio del derecho fundamental de un tercero, CREMER, W., Freiheitsgrundrechte, op. cit., pp. 171 y ss. Sobre los límites de perjuicio tolerable en los derechos fundamentales y la relatividad como condicionante de la protección, MURSWIEK, D., Die Staatliche Verantwortung für die Risiken der Technik, op. cit., pp. 91 y ss.

92 En ocasiones es suficiente obtener una declaración de la obligación de abstenerse de perjudicar los derechos fundamentales de terceras personas, MURSWIEK, D., Die Staatliche Verantwortung für die Risiken der Technik, op. cit., pp. 89 y ss. 
constitucionales abiertas o los derechos de configuración legal en materia de derechos de prestación, que eventualmente permitirían la estructuración de los efectos constitucionales en materia de protección de los derechos fundamentales en los casos concretos. La situación jurídica del titular del derecho fundamental frente a la infracción o peligro de injerencia implica que no se aplica por parte de los poderes públicos los instrumentos de vinculación positiva de carácter objetivo, es decir, acciones positivas de protección de un derecho fundamental, o no se realiza de forma efectiva y directa, existiendo una obligación previa de adoptar dichos instrumentos con carácter preventivo, con la consecuencia de que surge un derecho subjetivo a la protección a favor del titular, que se puede asegurar como elemento de garantía o como mecanismo de la efectividad del derecho. Este derecho subjetivo a la protección puede dar lugar a un reconocimiento de la protección o a la adopción directa de medidas de protección en ejecución de dicho reconocimiento, que, eventualmente, se pueden integrar en el sentido prescriptivo del derecho fundamental ${ }^{93}$. Este derecho a la protección se debe considerar un derecho de prestación en sentido amplio, que impone a los poderes públicos dotar de seguridad a los bienes constitucionales frente a perjuicios o amenazas de terceros en un sentido estricto ${ }^{94}$. Ahora bien, no se puede considerar un derecho autónomo de protección, que solo sería deducible de una regulación constitucional específica, sino instrumental del propio derecho fundamental en los supuestos que se puede decidir por el legislador o integrar de forma directa en la norma constitucional. En cualquier caso, la protección del supuesto normativo del derecho fundamental mediante normativa infraconstitucional se debe integrar en la posición jurídica constitutiva y en el ámbito de protección del derecho fundamental, con la consecuencia de que cualquier modificación restrictiva de la protección es infracción del propio derecho fundamental ${ }^{95}$. Una vez articulada la obligación de protección estatal, la abstención de protección se convierte en una infracción del derecho fundamental ${ }^{96}$.

93 Sobre la situación del titular del derecho tras la adopción de las medidas de vinculación positiva y la estructuración de un derecho de protección, ISENSEE, J., "Das Grundrecht als Abwehrrecht und als Schutzpflicht", en ISENSEE, J.-KIRCHHOF, P. (Hrsg.), Handbuch des Staatsrechts der Bundesrepublik Deutschland, Bd. V, op. cit., pp. 238 y ss. Sobre el derecho a la protección como consecuencia de un proceso de subjetivización de la obligación de protección, HERMES, G., Das Grundrecht auf Schutz von Leben und Gesundheit, op. cit., pp. 208 y ss., pp. 219 y ss.; KRINGS, G., Grund und Grenzen grundrechtlicher Schutzansprüche, op. cit., pp. 234 y ss. Sobre la jurisprudencia del Tribunal Constitucional alemán en materia de derecho fundamental a la protección, DOMÉNECH PASCUAL, G., Derechos fundamentales y riesgos tecnológicos, op. cit., pp. 77 y ss.

94 Vid. DOMÉNECH PASCUAL, G., Derechos fundamentales y riesgos tecnológicos, op. cit., pp. 69-70, p. 72. Sobre la articulación de la obligación de protección como una obligación de prestación, es decir, como acción de contenido positivo que deben realizar los poderes públicos, MURSWIEK, D., Die Staatliche Verantwortung für die Risiken der Technik, op. cit., pp. 123 y ss.

95 LÜBBE-WOLFF, G., Die Grundrechte als Eingriffsabwehrrechte, Nomos Verlag, Baden-Baden, 1988, pp. 125 y ss.

96 MURSWIEK, D., Die Staatliche Verantwortung für die Risiken der Technik, op. cit., pp. 106-107. 


\section{LOS EFECTOS DE LA VINCULACIÓN POSITIVA DE CARÁCTER OBJETIVO EN LOS DERECHOS DE DEFENSA}

Los derechos de defensa se caracterizan en su contenido prescriptivo por la obligación de abstención de conductas y acciones por parte de los destinatarios que perjudiquen o infrinjan el objeto del derecho. Este contenido prescriptivo es una consecuencia de la vinculación negativa a la Constitución, convertida en una obligación generalizada para el poder público y el conjunto de los ciudadanos (art. 9.1 CE), en el sentido de prohibir la adopción de decisiones o la realización de actos contrarios a los derechos fundamentales con la finalidad de impedir que se perjudiquen a los titulares en el ámbito de protección de su derecho. Los derechos de defensa tienen un efecto reflejo que se concreta en la posibilidad de que el titular emprenda acciones encaminadas a la protección del derecho. Este efecto reflejo puede ser la consecuencia de una previsión constitucional concreta y específica a través de un proceso jurisdiccional de carácter especializado (en nuestro caso amparo ordinario y constitucional - art. 53.2 CE) o de carácter genérico que se concreta en la posibilidad de alegar ante la jurisdicción ordinaria y por procedimientos judiciales ordinarios la protección del derecho ${ }^{97}$, en el bien entendido de que los derechos fundamentales se aplican como normas jurídicas con independencia de su grado de desarrollo normativo, ya que son susceptibles de protección a partir de su consideración como normas directamente aplicables ${ }^{98}$.

En definitiva, cuando como consecuencia directa del efecto reflejo se intenta proteger un derecho de defensa, los poderes públicos deben proteger los derechos básicamente frente a actos del propio Estado, pero cuando se establece una protección específica para un derecho, los poderes públicos deben proteger los derechos de defensa frente a actos que en muchas ocasiones son ajenos al propio aparato del Estado, aunque no excluidos, articulándose, en consecuencia, mecanismos de aplicación de los derechos fundamentales a relaciones de carácter social o privado.

En resumen, los derechos de defensa protegen un bien jurídico identificado, un ámbito de protección de un derecho fundamental frente a intervenciones del poder público o de personas privadas. En este sentido, los derechos de defensa son oponibles en procesos específicos de protección, sin que se requiere nuevas normas distintas a la articulación constitucional de los derechos fundamentales para desarrollar las pretensiones de protección como consecuencia de la vinculación negativa, pero también posibilita que se articulen medidas de vinculación positiva por parte de los poderes públicos a través de

$97 \mathrm{Tal}$ como sucede con los derechos de defensa integrados en la sección $2 .^{a}$ del capítulo $2 .^{\circ}$ del Titulo I CE

98 En cualquier caso, se debe tener en cuenta que en otros ordenamientos jurídicos la apertura a la protección jurisdiccional ordinaria puede estar prevista de forma expresa en la Constitución tal como sucede en el art. 19.4 LFB o bien tal como sucede en el caso italiano los mecanismos de protección se articulan exclusivamente a través de procesos jurisdiccionales ordinarios y no especializados. 
acciones que permitan desarrollar deberes positivos de los propios poderes públicos o eventualmente mecanismos de protección positiva de los derechos frente a acciones de personas privadas o de los propios poderes públicos ${ }^{99}$.

Las relaciones de la vinculación positiva con los derechos de defensa puede dar lugar a diversos mecanismos de protección o de dotación de eficacia de carácter específico como el sometimiento a autorización administrativa para un reconocimiento pleno del derecho, el sometimiento a un procedimiento de vigilancia y supervisión mediante el registro del ejercicio o mediante el control por una administración independiente, la declaración de conductas perturbadoras del derecho fundamental por autoridades independientes, el fomento de los derechos mediante medidas de financiación o de acción positiva, la subvención, la redistribución impositiva o las acciones en fomento de determinados bienes como la protección de la salud y, sobre todo, el control judicial mediante acciones específicas para evitar perjuicios y puestas en peligro del ejercicio de los derechos fundamentales.

La vinculación positiva de los derechos de defensa se conecta a la necesidad de ofrecer seguridad a los ciudadanos como objeto de la acción de los poderes públicos, que se concreta en el derecho de los ciudadanos a ser protegidos en sus derechos fundamentales y que se corresponde como contrapartida a la obligación de los ciudadanos de realizar tareas o prestar servicios personales a favor del Estado y contribuir a las cargas. En la relación que se establece entre Estado y ciudadano, los poderes públicos deben garantizar a cambio de dichas obligaciones de los ciudadanos, la seguridad interna para proteger al ciudadano en su existencia física y sus derechos frente a intervenciones en los mismos de terceras personas.

En los conflictos entre derechos, a menudo se olvida que las intervenciones normativas o ejecutivas de los derechos fundamentales se justifican por la protección de otros derechos fundamentales de terceras personas, es decir, la protección, la vinculación positiva y efectiva de los derechos fundamentales se obtiene mediante intervención o restricción de derechos, de forma que la protección y efectividad de un derecho se establece mediante la intervención en otro. En este proceso, se debe analizar y diferenciar la protección que se despliega a través de la intervención a favor de un derecho fundamental, del hecho mismo de la intervención o restricción que supone para otro derecho fundamental ${ }^{100}$.

Este proceso de protección a través de la intervención requiere una decisión del legislador adoptada en desarrollo de la obligación de protección de

99 Un resumen sobre la relación de los derechos de defensa con la obligación de protección estatal, POSCHER, R., Grundrechte als Abwehrrechte. Reflexive Regelung rechtlich geordeneter Freiheit, Mohr Siebeck, Tübingen, 2003, pp. 285 y ss. Sobre la interrelación entre los derechos de defensa y la obligación de protección estatal, KRINGS, G., Grund und Grenzen grundrechtlicher Schutzansprüche, op. cit., pp. 103 y ss.

100 Sobre la articulación de la idea de protección a través de intervención, WAHL, R.-MASING, J., "Schutz durch Eingriff", JZ, 1990, pp. 553 y ss. Un resumen de la problemática en UNRUH, P., Zur Dogmatik der grundrechtlichen Schutzpflichten, op. cit., pp. 80 y ss. 
los derechos de defensa que implica un reconocimiento expreso e implícito de la necesidad de adoptar una decisión normativa para la resolución de un conflicto o concurrencia entre derechos. El desarrollo normativo determinará en el caso concreto el alcance de la protección y de la restricción de los derechos fundamentales afectados.

En cierto sentido, la protección a través de la intervención implica que los derechos de defensa dejen de estructurarse a partir de la relación bilateral tradicional entre titulares y poderes públicos para articularse y estructurarse en una relación tridimensional a partir de los titulares, los poderes públicos y terceros que pueden afectar o infringir los derechos fundamentales ${ }^{101}$.

Por otra parte, la articulación de medidas de intervención para determinar la protección de los derechos de defensa implica un cambio en el contenido prescriptivo de los propios derechos de defensa, ya que las medidas de vinculación positiva no se fundamentan en la tradicional obligación de abstención de actos de perjuicio en los derechos fundamentales, sino en la articulación de obligaciones positivas exigidas al legislador, pero también mediante el control de las acciones que deben desarrollar el resto de los poderes aplicadores del Derecho 102

Estas medidas de vinculación positiva conectadas a una intervención en los derechos de defensa implica la aplicación por parte del poder público de medios de coacción y de imposición de conductas para garantizar la protección de determinados derechos. En estos casos, las acciones positivas realizadas por los poderes públicos exigen formas jurídicas de intervención previstas previamente en la ley como principal instrumento de estructuración de medidas de protección y dotación de eficacia a los derechos fundamentales, pero adoptadas en la práctica mediante acto administrativo o sentencia. La finalidad de estas acciones positivas es vincular y dotar de eficacia a los derechos de defensa, aunque deba restringir y condicionar el alcance potencial del otro derecho fundamental. Estas medidas de intervención requieren la necesidad de que se produzca la inmediatez del perjuicio del derecho de defensa, es decir, un perjuicio directo que sea equivalente a una infracción del derecho fundamental.

En general, la dimensión objetiva de los derechos fundamentales ha contribuido a la superación de las características tradicionales de la intervención, en el sentido de que la relevancia tradicional para los derechos fundamentales de las medidas y decisiones estatales, implica que no solo sean decisiones y acciones de restricción, sino también de protección y dotación de eficacia frente a otros posibles perjuicios ocasionados por personas no integradas en el poder público. En este sentido, se desprende una segunda consecuencia, ya que se debe integrar en el concepto de intervención para admitir que se puede basar en una acción positiva como en una abstención ${ }^{103}$. Tradicionalmente se

101 Sobre la relación tridimensional de los derechos de defensa, WAHL, R.-MASING, J., "Schutz durch Eingriff", op. cit., p. 556.

102 Vid. WAHL, R.-MASING, J., "Schutz durch Eingriff", op. cit., pp. 558 y ss.

103 ECKHOFF, R., Der Grundrechtseingriff, Heymann, Köln [u.a.], 1992, p. 273 
planteaban dificultades sobre la posibilidad de intervenciones a través de la abstención en la actuación del poder público, ya que una acción que no se ha realizado materialmente carece de consecuencias, es decir, se plantea una problema de causalidad en el perjuicio ${ }^{104}$. La pluridimensionalidad de los derechos fundamentales, ha permitido deducir que es posible una intervención a través de la abstención cuando la obligación de actuación del poder público se ha establecido mediante ley $^{105}$, de forma que el incumplimiento de la obligación de actuación ocasiona el perjuicio que solo es posible a través de omisiones del poder ejecutivo o del poder judicial ${ }^{106}$. En definitiva, se produce la intervención tras una previa obligación legal de actuación no realizada por los poderes aplicadores del derecho, de forma que el incumplimiento de la obligación de protección deviene en una infracción del derecho fundamental.

\section{LOS EFECTOS DE LA VINCULACIÓN POSITIVA DE CARÁCTER OBJETIVO EN LOS DERECHOS DE PRESTACIÓN}

Los derechos de prestación debe ser definidos y estructurados previamente en función de un determinado contenido, para que una pretensión de su protección sea ejecutable jurídicamente, es decir, se deben articular, desarrollar y concretar normativamente las circunstancias y contenido de dicha prestación ${ }^{107}$. El derecho de prestación en sentido amplio es sinónimo de pretensión de acciones de los poderes públicos, pudiéndose incluir en este concepto marco tanto a los derechos sociales, vinculados a una acción fáctica del destinatario y susceptibles de articularse en términos de acciones positivas, como los derechos con una dimensión de carácter organizativo y procedimental, vinculados a una decisión pública del poder público e interrelacionados con la necesidad de articular una configuración legislativa sobre el objeto, el alcance y el contenido de los distintos derechos conectados a la categoría $^{108}$, que en ocasiones alcanza a algunos derechos tradicionalmente incluidos entre los derechos de defensa.

Los derechos de prestación implican una heterogeneidad de criterios materiales que pueden ir desde la protección de la garantía de plazas escolares gra-

104 ECKHOFF, R., Der Grundrechtseingriff, op. cit., p. 279

105 LÜBBE-WOLFF, G., Die Grundrechte als Eingriffsabwehrrechte, op. cit., pp. 33-34 y 75-76.

106 Sobre obligaciones de actuación del Estado contra abstenciones, ECKHOFF, R., Der Grundrechtseingriff, op. cit., p. 292

107 Sobre los derechos de prestación, REQUEJO PAGES, J. L., "Derechos de prestación", en ARAGÓN REYES, M. (coord.), Temas básicos de Derecho Constitucional, Tomo III, Civitas, Madrid, 2001, pp. 221-223; COSSÍO DÍAZ, J. R., Estado social y derechos de prestación, CEC, Madrid, 1989; PORRAS RAMÍREZ, J. M., "Caracterización y garantía de los derechos de prestación en el Estado constitucional, en AAVV, Derecho constitucional y cultura. Estudios en homenaje a Peter Häberle, Tecnos, Madrid, 2004, pp. 659 y ss. Una visión general reciente de los derechos de prestación en la doctrina alemana en BOROWSKI, M., "Grundrechtliche Leistungsrechte", JöR, 2002, núm. 50, pp. 301 y ss.

108 Forsthoff plantea que el derecho de prestación es un concepto contrapuesto al de derecho de defensa en general o al derecho de libertad en particular, ya que el derecho de presta- 
tuitas, al ingreso o acceso a las instituciones públicas, a un mínimo de existencia, a la configuración de estructuras organizativas y procedimentales para ejercer derechos, hasta el desarrollo de medidas frente a coacciones de terceras personas ${ }^{109}$. A pesar de que desde el respectivo contenido prescriptivo los derechos de defensa y los derechos de prestación se relacionen a través de un principio de exclusión mutua ${ }^{110}$, lo cierto es que desde un punto de vista material aparecen frecuentemente interrelacionados ${ }^{111}$, ya que la dimensión organizatoria y procedimental de cualquier derecho, incluidos los derechos de defensa, o incluso la dimensión social de algunos derechos de defensa, no deja de ser una prestación de carácter normativo o fáctico que debe realizar el Estado ${ }^{112}$, pero que no impide que pueda seguir caracterizando el contenido prescriptivo principal del derecho afectado como estrictamente incluido entre los derechos de defensa. Desde un punto de vista material es importante caracterizar la tendencia principal del contenido prescriptivo de cada derecho para determinar su inclusión en una u otra categoría, a pesar de que con posterioridad se puedan determinar elementos prescriptivos que se muevan en el otro tipo de derechos.

De todos modos, se debe insistir en la idea de que un análisis a partir del carácter material de los derechos fundamentales implica una interrelación dogmática de los derechos de defensa y de prestación, ya que las decisiones públicas son necesarias para la garantía de ambos tipos de derechos, siendo necesarias prestaciones de carácter jurídico para desarrollar el contenido de protección de los derechos fundamentales ${ }^{113}$. La protección de los derechos que se debe desarrollar tanto frente a los aspectos de configuración como de

ción implica la producción positiva de comportamientos, debido a que cualquier forma de prestación, organización o participación requiere actuaciones positivas a través de prestaciones, instituciones o procedimientos. Sobre el Estado social, APARICIO PÉREZ, M.A., “El Estado social en la jurisprudencia del Tribunal Constitucional", en CAMARA VILLAR, G. y CANO BUESO, J., Estudios sobre el Estado social, Tecnos y Parlamento de Andalucía, Madrid, 1993; DIEZ MORENO, F., El Estado social, Centro de Estudios Políticos y Constitucionales, Madrid, 2004; FERNANDEZ-MIRANDA CAMPOAMOR, A., "El Estado social”, REDC, 2003, núm. 69, pp. 139 y ss.; GONZÁLEZ MORENO, B., El Estado Social. Naturaleza jurídica y estructura de los derechos sociales, Civitas, Madrid, 2002, pp. 27 y ss.; FORSTHOFF, E., Problemas actuales del Estado social de derecho en Alemania, Centro de Formación y Perfeccionamiento de funcionarios, Madrid, 1966; FORSTHOFF, E., "Problemas constitucionales del Estado social", en ABENDROTH, W., FORSTHOFF, E., DOEHRING, K., El Estado social, Centro de Estudios Constitucionales, Madrid, 1986; FORSTHOFF, E., "Concepto y esencia del Estado social de derecho", en ABENDROTH, W.-FORSTHOFF, E.-DOEHRING, K., El Estado social, Centro de Estudios Constitucionales, Madrid, 1986; RUBIO LARA, M. ${ }^{a}$ J., La formación del Estado social, Ministerio del Trabajo y de la Seguridad Social, Madrid, 1991.

109 LINDNER, J. F., Theorie der Grundrechtsdogmatik, op. cit., pp. 453 y ss.

110 Sobre el principio de exclusión mutua desde un punto de vista prescriptivo de los derechos de defensa y de prestación, LINDNER, J. F., Theorie der Grundrechtsdogmatik, op. cit., p. 451.

111 Sobre las dificultades de diferenciar materialmente los derechos de prestación y de defensa, ROTH, W., Faktische Eingriffe in Freiheit und Eigentum, op. cit., pp. 398 y ss.

112 Sobre la dimensión prestacional de los derechos fundamentales, LINDNER, J. F., Theorie der Grundrechtsdogmatik, op. cit., pp. 450 y ss.

113 Sobre la interrelación de los derechos de defensa y de prestación, LÜBBE-WOLFF, G., Die Grundrechte als Eingriffsabwehrrechte, op. cit., pp. 24 y ss. Sobre las pretensiones de prestación estatal vinculadas a los derechos de defensa, STERN, K., Das Staatsrecht der Bundesrepu- 
aplicación de las normas jurídicas, operando de forma paralela tanto en relación con los derechos de defensa como de prestación, pero que implica medidas positivas para su articulación que en sentido estricto se debe integrar en los aspectos prestacionales ${ }^{114}$. En este sentido, la vinculación positiva a los derechos fundamentales de los poderes públicos desempeña una función de nexo entre ambos tipos de derechos, ya que en caso contrario la consecuencia sería la desaparición de la utilidad de la distinción entre derechos de defensa y de prestación, a pesar de que sigue siendo operativa y descriptiva del contenido prescriptivo de ambos derechos. La complejidad y heterogeneidad de de los contenidos sustanciales no debería impedir seguir utilizando la distinción a partir de su significado primario prescriptivo.

Los derechos de prestación, a diferencia de los derechos de defensa, tienen como destinatario prácticamente exclusivo a los poderes públicos, por lo que se interrelaciona de forma directa con la vinculación positiva a los derechos fundamentales (art. 53.1 CE) ${ }^{115}$. El contenido prescriptivo conectado a los derechos de prestación implica la realización de acciones positivas por parte de los poderes públicos, de modo que se produce una integración en la vinculación positiva de carácter genérico de los poderes públicos ${ }^{116}$. En cualquier caso, las específicas y concretas acciones positivas de protección y dotación de eficacia a los derechos de prestación requieren concreción normativa adoptada por el legislador, pero al mismo tiempo estas acciones integran el contenido prescriptivo, las obligaciones y deberes que deben cumplir los poderes públicos como destinatarios de los derechos de prestación.

blik Deutschland. Bd. III/1, op. cit., pp. 728 y ss.; SCHLINK, B., "Freiheit durch Eingriffsabwehr Rekonstruktion der klassischen Grundrechtsfunktion", EuGRZ, 1984, Heft 17, pp. 457 y ss.; COSSÍO DÍAZ, J. R., Estado social y derechos de prestación, op. cit., pp. 190 y ss.

114 Sobre la inclusión de los aspectos de protección de los derechos en la dimensión prestacional, LÜBBE-WOLFF, G., Die Grundrechte als Eingriffsabwehrrechte, op. cit., pp. 421 y ss. Sobre el desarrollo de los derechos de libertad a través de la dimensión social, que implica regulaciones objetivas, prestaciones y dimensión organizativa y procedimental, SUHR, D., "Freiheit durch Geselligkeit. Institut, Teilhabe, Verfahren und Organisation im systematischen Raster eines neuen Paradigmas", EuGRZ, 1984, Heft 20, pp. 534 y ss.

115 No obstante, con carácter excepcional, y en ocasiones matizando incluso el propio carácter prestacional del derecho, pueden considerarse como destinatarios de estos derechos a las personas privadas como podría suceder en casos de restricciones de acceso a escuelas privadas subvencionadas o en materia del derecho a la tutela judicial efectiva en temas como el de la garantía de indemnidad. En conexión con este tema no se puede dejar de mencionar que muchos de los tradicionales derechos sociales, que no siempre tienen que tener carácter prestacional, solían tener como principal destinatario a las personas privadas, ya que sus infracciones se solían cometer en el transcurso de relaciones sociales como podía suceder con la prohibición del trabajo infantil o forzoso, el tiempo mínimo de vacaciones o la negociación colectiva. En la medida en que el destinatario no es el poder público, su indudable carácter imperativo o prescriptivo se ha articulado por la vía del tratado internacional o de decisiones legislativas, que salvo excepciones no aparecen recogidas en la Constitución, pero cuya efectividad y alcance de protección con el transcurso del tiempo no es cuestionada.

116 Sobre el contenido prescriptivo de los derechos de prestación, ARANGO, R., El concepto de derechos sociales fundamentales, op. cit., pp. 107 y ss.; GONZÁLEZ MORENO, B., El Estado Social, op. cit., pp. 129 y ss.; COSSÍO DÍAZ, J. R., Estado social y derechos de prestación, op. cit., pp. 235 y ss. 
Los derechos sociales se caracterizan por tener como contenido pretensiones de protección por parte de los poderes públicos con la finalidad de proteger intereses de miembros de la comunidad a través de acciones dirigidas a mejorar la situación general del individuo en la sociedad. Estos derechos pueden implicar mejoras de las condiciones vitales, una mejor distribución del producto social o una mejora de la participación en los bienes colectivos para reforzar las posiciones individuales. La función de producción, distribución y mejora de las condiciones vitales conectadas a los derechos sociales dependen no solo de las acciones y conductas de los destinatarios, sino también de criterios y hechos objetivos como la situación económica, coyuntural y presupuestaria de un Estado, por lo que existen condicionantes de su aplicación y operatividad práctica que implican que rijan con mayor intensidad los criterios de oportunidad política para su estructuración ${ }^{117}$.

Los derechos sociales presentan dificultades para ser caracterizados autónomamente como categoría jurídica, ya que su contenido prescriptivo es híbrido al poderse articular tanto como derecho de defensa o como derecho de prestación ${ }^{118}$. En todo caso, la vinculación positiva de los destinatarios de las mismas aparece más interrelacionada y de forma más directa con la obligación de realizar prestaciones de tipo fáctico por parte de los poderes públicos a favor de los titulares, aunque también se puede derivar obligaciones de protección estatal para imponer en la sociedad el respeto de alguno de sus contenidos como, por ejemplo, la prohibición del trabajo infantil.

Estos derechos sociales no son self-executing, ya que frecuentemente no se articulan desde un punto de vista constitucional como derechos subjetivos de los ciudadanos, de forma que precisan para fijar su alcance y configuración de

117 Sobre los derechos sociales, AAVV, Lecciones de derechos sociales, $2 .^{\text {a }}$ ed., Tirant Lo Blanch, Valencia 2004; APARICIO PÉREZ, M. Á., "Sobre la estructura de los derechos constitucionales en la Constitución española y otras acotaciones al respecto", en AAVV, Derechos constitucionales y pluralidad de ordenamientos, Cedecs, Barcelona, 2001; BALDASSARRE, A., Los derechos sociales, Universidad Extremado de Colombia, serie de teoría jurídica y filosofía del derecho $\mathrm{N}^{\circ}$ 20, Bogota, 2001; BOCKENFORDE, E.-W., Escritos sobre derechos fundamentales, Nomos Verlagsgesellschaft, Baden-Baden 1993; CASCAJO CASTRO, J. L., La tutela constitucional de los derechos sociales, CEC, Madrid, 1988; PRIETO SANCHIS, L., "Los derechos sociales y el principio de igualdad sustancial", Revista del Centro de Estudios Constitucionales, 1995, núm. 22, pp. 9 y ss.; GONZÁlEZ MORENO, B., El Estado Social, op. cit., pp. 69 y ss.; FREIXES SANJUÁN, T., Los derechos sociales de los trabajadores en la constitución, Ministerio del Trabajo y Seguridad Social, Madrid. 1986; RODRIGUEZ OLVERA, O., Teoría de los derechos sociales en la constitución abierta, Comares, Granada, 1998. Para un análisis reciente de los derechos sociales, estableciendo las interrelaciones con las distintas categorías, PISARELLO, G., Los derechos sociales y sus garantías. Elementos para una reconstrucción, Trotta, Madrid, 2007, en particular sobre la ausencia de diferencias estructurales con otros derechos fundamentales, pp. 79 y ss.

118 Desde un punto de vista de su contenido prescriptivo, los derechos sociales no son una categoría unitaria, SALAZAR, C., Dal riconoscimento alla garanzia dei diritti sociali. Orientamenti e tecniche decisorie della Corte costituzionale a confronto, G. Giappichelli, Torino, 2000, pp. 15 y ss. En general, sobre los derechos sociales en la Constitución Italiana, BALDASSARRE, A., "Diritti sociali”, AAVV, Enciclopedia giuridica, Istituto della Enciclopedia italiana (Treccani), Roma, 1988-1997, pp. 13 y ss. 
normas infraconstitucionales ${ }^{119}$. En cualquier caso, desde un punto de vista jurídico, no es imposible formular de forma precisa los derechos sociales, pudiéndose incluso articular pretensiones que sean aplicables directamente a favor de los ciudadanos. Las pretensiones económicas cuantificables como ayudas sociales, rentas mínimas, fomento de la formación pueden ser establecidas en la Constitución y a partir de dicho momento deben de ser consideradas como normas jurídicas. En este sentido, no es complicado o inalcanzable su establecimiento en la Constitución y la exigencia de su aplicación directa, pero deben responder, tal como se ha mencionado, a necesidades sociales que se quieran superar de forma permanente o que el poder público tenga la capacidad de su realización desde un punto de vista económico, tal como sucede, por ejemplo, en el derecho a la educación ${ }^{120}$. No obstante, también se reconocen muchos derechos sociales que se relacionan con una realidad cambiante, de forma que su formulación concreta en la Constitución debe tener la capacidad de adecuarse al cambio de situación sin ser necesaria una reforma constitucional ${ }^{121}$. Por este motivo el constituyente suele establecer y redactar fórmulas relativas, que caracteriza a los derechos sociales a través de configuraciones normativas abiertas, sobre todo en relación con prestaciones conectadas a la Seguridad Social y a la asistencia social, pero también al derecho al medio ambiente ${ }^{122}$.

119 Sobre el mecanismo de concreción de los derechos sociales, MURSWIEK, D., Die Staatliche Verantwortung für die Risiken der Technik, op. cit., pp. 264 y ss. Sobre al incidencia de la teoría externa en la configuración de los derechos sociales, BOROWSKI, M., Grundrechte als Prinzipien, Baden-Baden, Nomos Verlag, 1998, pp. 303 y ss. Sobre las condiciones necesarias para que los derechos sociales adquieran el carácter de derechos fundamentales, BALDASSARRE, A., "Diritti sociali", AAVV, Enciclopedia giuridica, op. cit., pp. 28 y ss. Sobre la justicialidad de los derechos sociales, SALAZAR, C., Dal riconoscimento alla garanzia dei diritti sociali, op. cit., pp. 127 y ss.

120 En cualquier caso, aunque no sea frecuente la redacción concreta de derechos sociales, se ha reconocido el derecho a la educación básica, obligatoria y gratuita, pero también entre los derechos sociales abundan las normas prescriptivas de carácter imperativo y social como la prohibición de trabajo infantil o forzoso, el tiempo mínimo de vacaciones, la negociación colectiva e incluso en algunos sistemas la coparticipación de los trabajadores en las decisiones empresariales. En la doctrina, Cossío para la Constitución Española solo reconoce como derechos de prestación en sentido estricto al derecho a la educación y al derecho al trabajo. Vid. COSsíO DÍAZ, J. R., Estado social y derechos de prestación, op. cit., p. 226.

121 Sobre las relaciones de los derechos sociales con la situación jurídica y política, MURSWIEK, D., Die Staatliche Verantwortung für die Risiken der Technik, op. cit., pp. 267 y ss. Sobre el alcance y la interrelación con el legislador de los derchos sociales, TOMANDL, Th., Der Einbau sozialer Grundrechte in das positive Recht, J.C.B. Mohr (Paul Siebeck), Tübingen, 1967, pp. 20 y ss.

122 Sobre la delimitación de los derechos fundamentales de prestación, COSSíO DÍAZ, J. R., Estado social y derechos de prestación, op. cit., pp. 120 y ss. En general, los ámbitos materiales que se consideran protegidos por los derechos sociales serían el mínimo vital, la salud y asistencia sanitaria, la educación, la vivienda, el trabajo y la seguridad social contributiva y no contributiva. Vid. sobre dicha delimitación, ARANGO, R., El concepto de derechos sociales fundamentales, op. cit., pp. 212 y ss. En dicha delimitación se podía incluir los aspectos individuales del derecho al medio ambiente, vid. CANOSA USERA, R., Constitución y medio ambiente, Dykinson, Madrid, 2000; LOPERENA ROTA, D., El derecho al medio ambiente adecuado, Civitas, Madrid, 1996; RUIZ-RICO RUIZ, G., El derecho constitucional al medio ambiente: dimensión jurisdiccional, Tirant Lo Blanch, Valencia, 2000. 
En definitiva, la categoría de derechos sociales no permite desarrollar en nuestra Constitución impositivamente una serie amplia de acciones fácticas que deban cumplir los poderes públicos como destinatarios, ya que básicamente se limitan a las deducibles a partir del derecho a la educación. La vinculación positiva de carácter objetivo de los derechos sociales no permite desarrollar diferencias estructurales significativas cuando se compara con la vinculación positiva en los derechos de defensa, ya que las acciones positivas de protección y dotación de eficacia deben ser adoptadas por el legislador y eventualmente aplicadas por la administración, aunque como peculiaridad de los derechos sociales se puede destacar que el poder judicial no realiza acciones positivas de protección de su contenido al margen de las que se puedan desarrollar a partir de mecanismos de control de las resoluciones administrativas de reconocimiento y aplicación del contenido de los respectivos derechos sociales.

Finalmente, se debe analizar en este apartado la dimensión organizativa y procedimental de los derechos fundamentales que implica que requieran de algún tipo de organización, proceso o procedimiento para poder desplegar y articular su ámbito de protección, que es determinado a través de la ley. Esta articulación de carácter organizativo y procedimental pueden ser aplicada a los derechos de prestación de carácter puro, ya que su contenido prescriptivo exige que el poder público realice como destinatario alguna acción que generalmente son decisiones públicas en determinadas condiciones (actos administrativos o sentencias), o bien puede aplicarse a los derechos de defensa caracterizados como derechos de configuración legal, en los que la estructuración de su ámbito de protección requiere de configuración normativa o decisiones legislativas. En ambos casos la vinculación positiva alcanza a la articulación de las acciones positivas concretas que deben desarrollar los poderes públicos con la finalidad de proteger o dotar de eficacia dichos derechos, configurando el alcance concreto de su contenido prescriptivo o los elementos organizatorios o procedimentales que implican decisiones de los poderes públicos cuyo control se integra en el ámbito de protección de los correspondientes derechos fundamentales ${ }^{123}$.

En definitiva, la dimensión organizativa y procedimental de los derechos fundamentales implican prescriptivamente una obligación positiva para los poderes públicos como destinatario con independencia de que se haya concretada en el texto constitucional. En este sentido, son derechos que implican una

123 Con carácter general, sobre la dimensión organizativa y procedimental de los derechos fundamentales, BOROWSKI, M., Grundrechte als Prinzipien, op. cit., pp. 320 y ss.; DOLDERER, M., Objektive Grundrechtsgehalte, op. cit., pp. 232 y ss; LINDNER, J. F., Theorie der Grundrechtsdogmatik, op. cit., pp. 452 y ss.; BETHGE, H., Zur Problematik der Grundrechtskollisionen, Verlag Franz Vahlen, München, 1977, pp. 2 y ss.; MURSWIEK, D., Die Staatliche Verantwortung für die Risiken der Technik, op. cit., pp. 249 y ss.; STERN, K., Das Staatsrecht der Bundesrepublik Deutschland. Bd. III/1, op. cit., pp. 953 y ss. En la doctrina austriaca, HOLOUBEK, M., Grundrechtliche Gewährleistungspflichten, op. cit., pp. 328 y ss. Sobre la integración de la configuración normativa en los derechos fundamentales, GARCÍA ROCA, J., Cargos públicos representativos. Un estudio del artículo 23.2 de la Constitución, Aranzadi, Pamplona, 1999, pp. 185 y ss. 
pretensión de ejecución o de acción relacionada con procedimientos judiciales o administrativos, la colaboración en determinadas organizaciones o incluso la articulación o configuración de dichas organizaciones o procedimientos. En resumen, la dimensión organizativa y procedimental afectaría a derechos fundamentales que requieren una actuación positiva del Estado para articular el supuesto de hecho o el objeto material de protección del derecho o incluso para fijar el alcance del contenido prescriptivo o del ámbito de protección ${ }^{124}$.

La vinculación positiva de los derechos fundamentales implica el análisis en este apartado de la protección de los derechos fundamentales a través de la organización y el procedimiento. En este sentido, se podrían considerar las medidas estatales como instrumentos para deducir derechos a la protección jurídica articuladas a través de normas legales de carácter sustancial como policiales, penales, organizativas y procedimentales y, en general, las pretensiones de protección frente a intervenciones de terceros interrelacionadas con los derechos fundamentales. Esta dimensión organizativa y procedimental de los derechos fundamentales tiene carácter prestacional, con independencia de que afecte o no a los derechos de defensa, pero no depende en su estructuración ni se vincula en su protección a la coyuntura económica. No obstante, en caso de ausencia de control de constitucionalidad de la omisión legislativa, permiten derivar una protección constitucional interpuesta en materia de amparo, generalmente de carácter mínimo, dada la ausencia de desarrollo normativo a través del mecanismo de la aplicación directa ${ }^{125}$.

La vinculación positiva de carácter objetivo conectada a la dimensión organizativa y procedimental de los derechos fundamentales implica la adopción de regulaciones de diverso tipo para la articulación de procedimientos de ejecutabilidad efectiva de determinados derechos fundamentales, para determinar y especificar el papel del juez y su relación con la protección de derechos concretos o para articular la protección efectiva del derecho. Al mismo tiempo se ha reconocido la relevancia para determinados derechos fundamentales del procedimiento administrativo con carácter prejudicial, ya que sometiendo a condiciones o siendo necesarias resoluciones expresas o implícitas para realizar un pleno ejercicio de dichos derechos fundamentales. Estas reglas procedimentales deben ser establecidas mediante criterios generales y abstractos a través de la ley integrándose como elemento esencial del derecho fundamental, sin que sean admisibles referencias individuales y concretas para determinar el ejercicio del derecho ${ }^{126}$.

124 Sobre la realización de los derechos fundamentales a través de la acción de los poderes públicos, DENNINGER, E., "Staatliche Hilfe zur Grundrechtsausübung durch Verfahren, Organization und Finanzierung", en ISENSEE, J.-KIRCHHOF, P. (hrsg.), Handbuch des Staatsrechts der Bundesrepublik Deutschland, Bd. V, C.F. Müller Verlag, Heidelberg, 1992, pp. 292 y ss.

125 Sobre la relación entre la vinculación positiva y la dimensión organizativa-procedimental de los derechos fundamentales, DENNINGER, E., "Staatliche Hilfe zur Grundrechtsausübung durch Verfahren, Organization und Finanzierung,, en ISENSEE, J.-KIRCHHOF, P. (hrsg.), Handbuch des Staatsrechts der Bundesrepublik Deutschland, Bd. V, op. cit., pp. 295-296.

126 STC 18/1987 FJ 6 
La vinculación positiva en el fondo implica un planteamiento de ejercicio de los derechos fundamentales a través de los poderes públicos, superando el planteamiento clásico y tradicional de que los derechos se tenían frente al Estado para protegerse de la actuación de los poderes públicos. En este sentido, la vinculación positiva cumple la función de describir y es el instrumento para articular la relevancia que han adquirido las regulaciones procesales y materiales de carácter organizativo para la defensa de los derechos, al articular las acciones positivas que deben emprender los poderes públicos con la finalidad de desarrollar dicha protección.

En este sentido, la vinculación positiva de carácter objetivo permite articular una obligación del Estado de establecer reglas de organización y procedimiento en todos los derechos que precisen una aplicación y una proyección externa de carácter necesario, no solo para la configuración material de los tradicionales institutos de derecho privado (propiedad, matrimonio y herencia), sino también para regular otros derechos como los de asociación, reunión, acceso a cargos públicos, la resolución de conflictos entre derechos, la protección directa de derechos fundamentales o la protección de bienes de interés general previstos por la Constitución. Estas regulaciones procedimentales superan a las autorizaciones de regulación y desarrollo material de carácter más tradicional como eran la reserva de ley, el principio de legalidad, el procedimiento administrativo y los procedimientos de protección judicial. En estos casos, la articulación de las reglas organizativas y procedimentales de carácter prestacional cumple la función de facilitar el ejercicio del derecho fundamental resultante. De todos modos, el legislador no puede regular, ni imponer condiciones de ejercicio de los derechos fundamentales con procedimientos y formularios que sean arbitrarios, ya que, aunque tengan por objeto proteger bienes constitucionales, no pueden ser tan rígidos que en la práctica hagan imposible el ejercicio de los derechos fundamentales ${ }^{127}$.

La dimensión organizativa de los derechos fundamentales implica la articulación de estructuras de carácter institucional o la estructuración de criterios prácticos para facilitar la realización y el ejercicio de los derechos de carácter colectivo. En este sentido, las medidas organizativas deben facilitar que se pueda llegar a una unidad de decisión en la colectividad a través de medidas de orden interno como la necesidad de establecer competencias, órganos, derechos de los individuos y control sobre las decisiones colectivas. Por su parte, la dimensión procedimental de los derechos implica la estructuración de reglas y procedimientos para poder llegar, alcanzar o determinar un resultado. En esencia, la dimensión organizativa y procedimental, aunque se puedan separar y diferenciar en un sentido estricto ${ }^{128}$, suelen ser analizadas de forma conjunta, ya que en numerosos derechos organizar un ejercicio

127 STC 332/1994 FJ 5

128 Sobre la necesidad de diferenciar entre la dimensión organizativa y procedimental, STERN, K., Das Staatsrecht der Bundesrepublik Deutschland. Bd. III/1, op. cit., pp. 959 y ss.; CREMER, W., Freibeitsgrundrechte, op. cit., pp. 393 y ss. 
es someterlos a procedimientos para ordenar el ejercicio de los derechos fundamentales ${ }^{129}$.

En definitiva, la vinculación positiva de carácter objetivo conectada con la dimensión organizativa y procedimental implica la estructuración de acciones positivas por parte de los poderes públicos, de forma que la inactividad o el cumplimiento incorrecto de estas medidas de estructura organizativa y procesal implican una infracción del derecho fundamental. Las normas procedimentales y organizativas no tienen rango constitucional, aunque son necesarias e imprescindibles para establecer las consecuencias del sentido prescriptivo de los derechos fundamentales, pudiendo, eventualmente, ser integrados los criterios deducibles de las mismas en la protección en amparo.

ABSTRACT. In the Spanish Constitution, the entailment to fundamental rights operates starting off a double scheme. Article 9.1 CE allows to deduce a negative entailment to the fundamental rights, that is to say, the duty of citizens and public powers of abstaining of any activity that harms the Constitution, which includes tacitly the fundamental rights. Article 53.1 CE settles down specifically the positive entailment to fundamental rights, that affects exclusively the public powers and it consists, first, in a general duty of carrying out its own functions in conformity with the Constitution and, second, in a mandate of developing the effectiveness of the fundamental rights in the sense of establishing its full realization. This article carries out an analysis of the positive entailment, distinguishing and treating the consequences through their subjective or objective implications. The subjective positive entailment has the purpose of determining the consequences for the public powers' functions that we will distinguish in the three classic powers: legislative, executive and judicial. The objective positive entailment should determine the effects that take place materially to fundamental rights: distinguishing between the defense rights and those of benefit.

129 En general sobre la dimensión organizativa y procedimental de los derechos fundamentales, DOLDERER, M., Objektive Grundrechtsgehalte, op. cit., pp. 235 y ss.; DENNINGER, E., "Staatliche Hilfe zur Grundrechtsausübung durch Verfahren, Organization und Finanzierung", en ISENSEE, J.-KIRCHHOF, P. (hrsg.), Handbuch des Staatsrechts der Bundesrepublik Deutschland, Bd. V, op. cit., pp. 296-297; BOROWSKI, M. Grundrechte als Prinzipien, op. cit., pp. 321 y ss.; GELLERMANN, M., Grundrechte in einfachgesetzlichem Gewande, op. cit., pp. 255 y ss. Sobre el conjunto de efectos deducibles de la dimensión organizativa y procedimental, STERN, K., Das Staatsrecht der Bundesrepublik Deutschland. Bd. III/I, op. cit., pp. 974 y ss. 